\title{
DEVELOPMENT OF CONTINUOUS SOLVENT EXTRACTION PROCESSES FOR COAL DERIVED CARBON PRODUCTS DE-FC26-03NT41873
}

\author{
Quarterly Report \\ PERIOD OF PERFORMANCE: \\ January 1, 2007 - March 31, 2007 \\ Submission date: \\ May 1, 2007 \\ Principal Investigator: \\ Elliot B. Kennel \\ Co-Investigators:
}

Dady B. Dadyburjor, Charles W. Kling, Liviu Magean, J. Joshua Maybury, Robert C. Svensson, Alfred H. Stiller, John W. Zondlo

\author{
West Virginia University \\ Department of Chemical Engineering \\ College of Engineering and Mineral Resources \\ PO Box 6102 \\ Morgantown WV 26506 \\ Subcontractors: \\ GrafTech International \\ 12900 Snow Road \\ Parma, OH 44130 \\ Koppers Inc. \\ 1005 William Pitt Way \\ Pittsburgh, PA 15238
}




\section{DISCLAIMER:}

This report was prepared as an account of work sponsored by an agency of the United States Government. Neither the United States Government nor any agency thereof, nor any of their employees, makes any warranty, express or implied, or assumes any legal liability or responsibility for the accuracy, completeness, or usefulness of any information, apparatus, product, or process disclosed, or represents that its use would not infringe privately owned rights. Reference herein to any specific commercial product, process, or service by trade name, trademark, manufacturer, or otherwise does not necessarily constitute or imply its endorsement, recommendation, or favoring by the United States Government or any agency thereof. The views and opinions of authors expressed herein do not necessarily state or reflect those of the United States Government or any agency thereof. 


\section{TABLE OF CONTENTS}

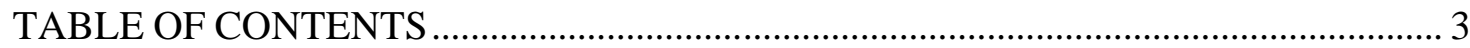

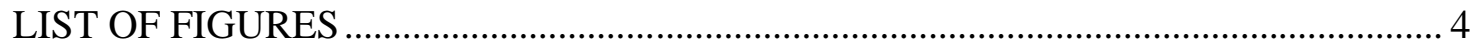

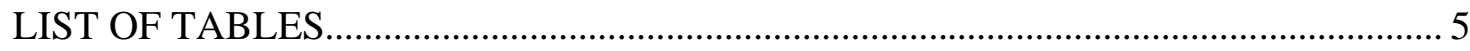

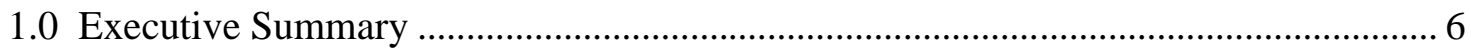

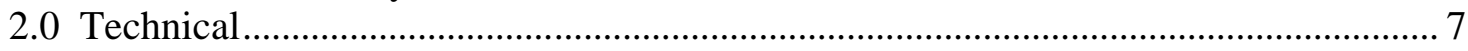

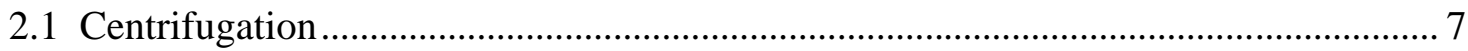

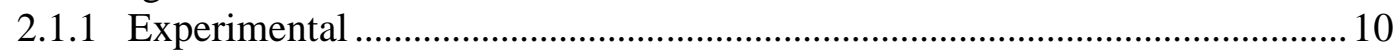

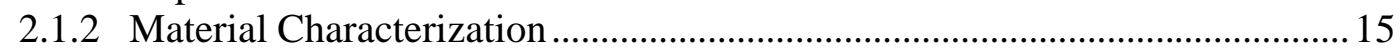

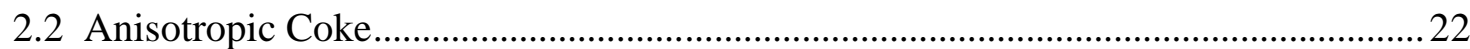

An alternate methodology is being considered for creating anisotropic grade (e.g., up to needle grade). The details of the operation of the process are being temporarily withheld pending submission of patents. However, the point is that the ability to increase anisotropy is being sought through variations in coke processing..................22

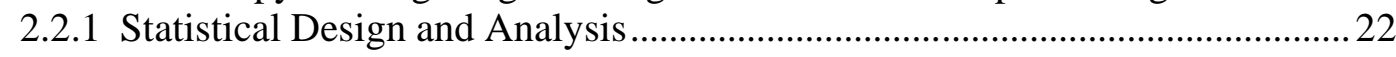

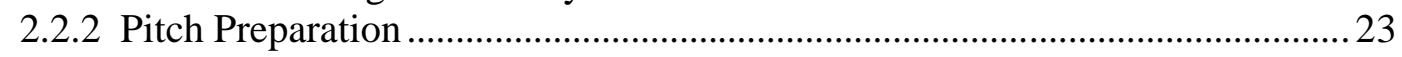

2.2.3 Abbreviated Protocol ........................................................................... 24

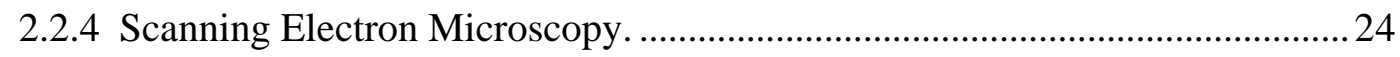

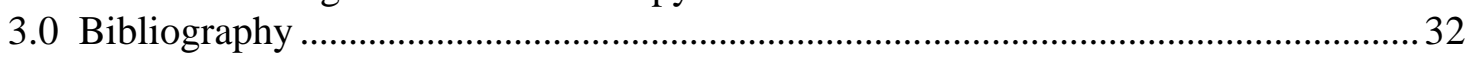

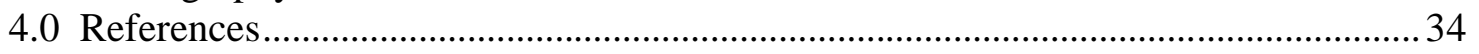




\section{LIST OF FIGURES}

Figure 1. Centrifuge Diagram (courtesy T. F. Hudgins Inc). ......................................... 8

Figure 2. Normalized Mass of Centrifuge Tails Produced as a Function of Centrifuge

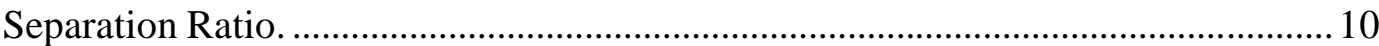

Figure 3. Centrifuge Rotational Velocity with SAE 30 Motor Oil Working Fluid at $75^{\circ} \mathrm{C}$.

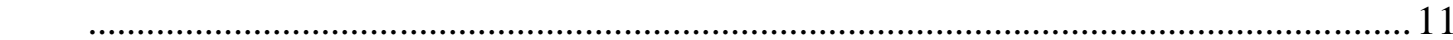

Figure 4. Centrifuge Rotational Velocity with Coal Slurry Working Fluid at $49^{\circ} \mathrm{C} \ldots \ldots . .11$

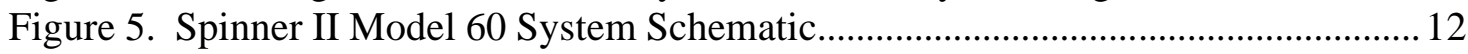

Figure 6. Spinner II Model 60 Centrifuge Experimental Setup.......................................... 12

Figure 7. Percent Ash in Coal Derived Tar over Centrifuge Time..................................... 13

Figure 8. Ash Content in Centrifuge Tails as a Function of Operating Time..................... 14

Figure 9. Centrifuge Separation Ratio $\xi$ as a Function of Operating Time....................... 14

Figure 10. Aromatic to Aliphatic Ratio from FTIR, Hydrogenated CTD, 2/13/07, $1^{\text {st }}$ Run.

Figure 11. Aromatic to Aliphatic Ratio from FTIR, Hydrogenated CTD, 2/13/07, $2^{\text {nd }}$

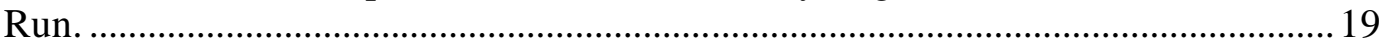

Figure 12. Aromatic to Aliphatic Ratio from FTIR, Hydrogenated CTD, 2/13/07, $3^{\text {rd }}$

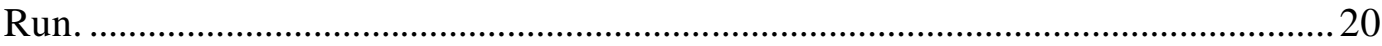

Figure 13. Aromatic to Aliphatic Ratio from FTIR, Hydrogenated CTD, $2 / 14 / 07,1^{\text {st }}$ Run.

Figure 14. Aromatic to Aliphatic Ratio from FTIR, Hydrogenated CTD, 2/14/07, $2^{\text {nd }}$

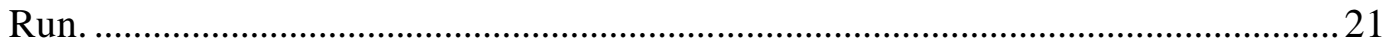

Figure 15. Aromatic to Aliphatic Ratio from FTIR, Hydrogenated CTD, 2/14/07, $3^{\text {rd }}$

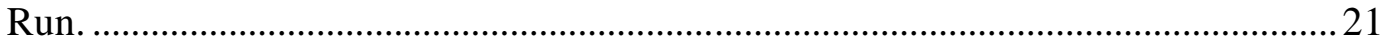

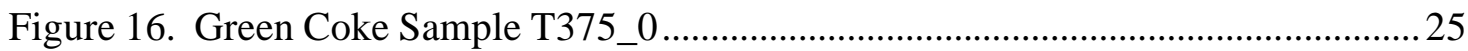

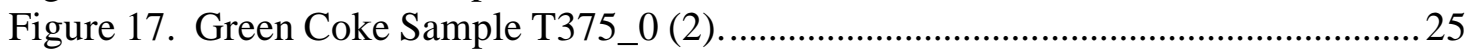

Figure 18. Green Coke from Alternative Process Sample T375_50................................ 26

Figure 19. Green Coke from Alternative Process Sample T375_100 ..................................26

Figure 20. Green Coke form Alternative Process Sample T425_50 …..............................27

Figure 21. Green Coke form Alternative Process Sample T425_100 ................................ 27

Figure 22. Randomness Function of d-Spacing.........................................................28

Figure 23. X-Ray Diffraction of Green Coke Samples (shown from 20 to 31 20) ..........29

Figure 24. XRD Intensity Curve with Separated Crystalline and Background Region ... 30

Figure 25. Crystalline Intensity Value as a Function of Temperature ...............................31

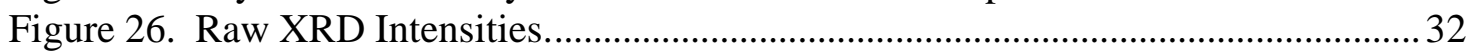

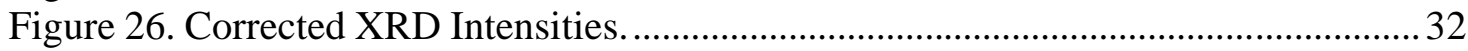




\section{LIST OF TABLES}

Table 1. Elemental Analysis of Raw Coal Tar Distillate as-Received from Koppers Inc.

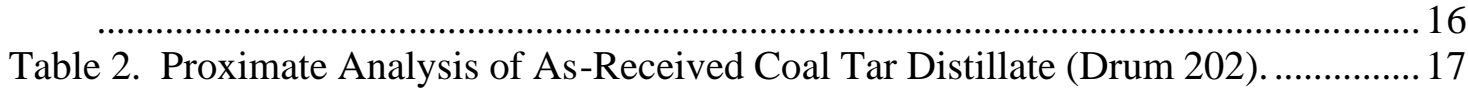

Table 3. Elemental Analysis of Kingwood Coal, $1^{\text {st }}$ Drum, As Received........................... 17

Table 4. Elemental Analysis of Kingwood Coal, $2^{\text {nd }}$ Drum, As Received. ........................ 18

Table 5. 2k Factorial Experimental Test Sequence (a) Experimental Values (b) ............. 22

Table 6. Proximate Analysis of Koppers Coal Tar Pitch.................................................. 23

Table 7. Thermogravimetric Analysis of Coal Tar Pitch Material.......................................2 24

Table 8. Mettler Softening Point of the Pitch Material ..................................................... 24

Table 9. Crystallite Dimensions of XRD 002 Peak...............................................................29

Table 10. Effects of Parameter Change as a Function of Crystallinity Difference ............31 


\subsection{Executive Summary}

The production of synthetic tar or synthetic crude from coal via direct liquefaction process results in the creation of slurries of hydrocarbon tar with solid matter, necessitating separation of the two phases. This paper describes the use of a commercially available, reaction-turbine style centrifuge to reduce the ash level in the synthetic tar product. The synthetic tar can then be converted to carbon products such as binder pitch or anode grade coke. Alternatively, synthetic tar can be refined to produce fuels products including gasoline, diesel, aviation fuel, etc. The ash-containing component has significant fuel value and is suggested as a possible fuel for coal gasification systems such as Fourteen.

For this study, a synthetic tar was created by dissolving powdered coal at about 50 mesh in a hydrogenated commodity solvent similar to naphthalene. Approximately $85 \%$ of the dry-ash free material was dissolved. The remainder is a solid phase material consisting primarily of mineral matter (ash) and fixed carbon. Hence centrifugation is required to separate the solid and liquid phases. Accordingly, a pressure vessel and return system were designed to allow continuous flow through the centrifuge. The return system operates using pressure differentials, enabling the system to be self-regulating. This return system allows the centrifuge to run continuously at a constant flow rate until acceptable ash levels are obtained in the product. Proximate Analysis was performed to determine ash levels of the product (centrate) and cake.

The centrifuged product can then be further processed and used for a variety of applications. Carbon Products at West Virginia University is currently researching ways to make electrode binder pitch from the centrifuged product and is also investigating liquid automotive fuels from coal. The centrifugation process is a necessary step for the production of carbon products from coal.

In addition, an alternate methodology is being considered for creating anisotropic grade (e.g., up to needle grade). The details of the operation of the process are being temporarily withheld pending submission of patents. The ability to increase anisotropy is being sought through variations in coke processing. 


\subsection{Technical}

Five drums of purified coal extract were accidentally destroyed by the WVU hazmat contractor. The drums were stored next to the room used for hazmat storage. Accordingly, It was decided in the future, product drums would be stored in facilities under the direct control of the WVU Carbon Products Group, and only commodity chemicals would be put in the storage facility. In the meantime, another 300 gallons of material needed to be produced.

It was determined that one gallon would be used for characterizations at Koppers Inc, and $200 \mathrm{lbs}$ ( 22 gallons) would be used for a pilot plant trial at GrafTech International Ltd. This requires distillation at Koppers and its partner (INTERTEKPARK) to $110^{\circ} \mathrm{C}$.

\subsection{Centrifugation}

Separation of solid materials from coal liquefaction-derived crude is problematic due to the tendency of heavy aromatic liquids to form viscous tarry phases. Solid particles, mainly consisting of mineral matter and fixed carbon, are often found suspended in the tarry phase. This makes conventional filtration problematic. For activities at the pilot scale and beyond, it is important to identify credible means for handling this problem.

A low cost solution was considered, based on the use of a centrifuge mass produced for use in large diesel engines to filter engine oil. For this research, a Spinner II Centrifuge (C. F. Hudgins, Houston TX 77292) was selected as a representative unit. The centrifuge is normally powered by the pressure differential between the high pressure oil line and the low pressure oil pan, so that oil flows through hollow spindle into rotating bowl (see Figure 1). As oil passes through the rotating bowl, centrifugal force separates the working fluid into two phases. The solid phase is deposited as a solid cake on the surface the cleanable bowl. Clean oil exits through opposing, twin nozzles that power the centrifuge, and returns to the crankcase from the level control base. Flows of up to 16 gpm can be accommodated by large units of this type, although for the experiments described herein, a smaller Model 60 unit rated at $0.8 \mathrm{gpm}$ was used. 


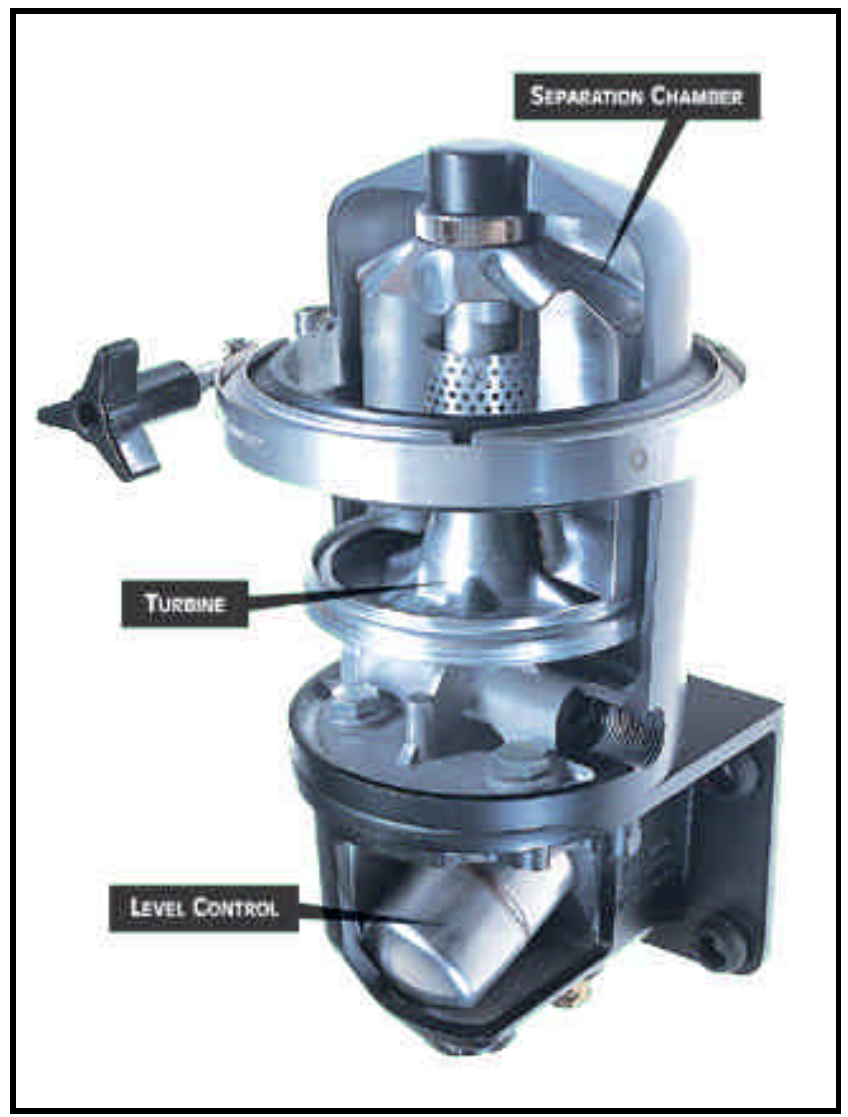

Figure 1. Centrifuge Diagram (courtesy T. F. Hudgins Inc).

The operation of the centrifuge separates the slurry into two components. The first component, referred to as the centrate, contains a reduced level of solids. The second component, referred to as the residue, contains an enhanced level of solids. Continuity requires that

$$
\mathrm{m}_{\mathrm{tot}}=\mathrm{m}_{\mathrm{c}}+\mathrm{m}_{\mathrm{t}} \quad,
$$

Where $m_{t o t}$ is the total initial mass of the slurry, $m_{c}$ is the mass of the liquid phase or "centrate," and $\mathrm{m}_{\mathrm{t}}$ is the mass of the solid phase or "tails". The ash content in the centrate is described by

$$
\mathrm{m}_{\mathrm{ash}, \mathrm{c}}=\mathrm{m}_{\mathrm{c}} \mathrm{C}_{\mathrm{ash}, \mathrm{c}} \quad,
$$

where the ash concentration in the centrate $C_{a s h, c}$ is determined by proximate analysis or some other appropriate technique. Likewise, the mass of ash in the tails is given by

$$
\mathrm{m}_{\mathrm{ash}, \mathrm{t}}=\mathrm{m}_{\mathrm{t}} \mathrm{C}_{\mathrm{ash}, \mathrm{t}} \quad \text {. }
$$

The centrifuge separation ratio $\xi$ is given by 


$$
\xi=\frac{C_{a s h, t}}{C_{a s h, c}}
$$

Thus a perfect centrifuge would be one in which $\xi$ tends toward infinity. The centrifuge separation ratio $\xi$ is likely not constant for most centrifuges but would likely vary according to the particle size distribution present in the centrifuge medium, the concentration, fluid viscosity and other parameters.

In the case of a direct liquefaction slurry, it is intended to create two main products. The centrate, i.e., a low-ash heavy liquid, would be used as a synthetic crude. The centrifuge tails would be coked to drive off volatile gas and nominated as a gasification fuel (e.g., for a coal gasifier such as FutureGen).

Because the tails are of much lower economic value than the centrate, it is desirable to maximize the relative yield of the centrate. A slurry made up of one part Lower Kittanning bituminous coal with a nominal ash content of $6 \%$, when dissolved in three parts coal tar distillate would exhibit an ash content of about $1.5 \%$. The required maximum ash content is $0.5 \%$ in order to create a precursor for a binder pitch extender (i.e., binder pitch would be produced by distilling the precursor and combining the distillation residue with other pitches in order to meet binder pitch specifications. Thus the problem can then be reduced to that of removing a quantity of ash equal to $1.0 \%$ of the total working fluid mass.

For example, a 55 gallon drum with $10 \%$ head space (total quantity of slurried working fluid 49.5 gallons), and an average density of $1.1 \mathrm{~kg} /$ liter would have a mass given by

$$
\begin{aligned}
& \mathrm{m}_{\text {tot }}=55 \mathrm{gal} * 8.3 \frac{\mathrm{lb}}{\mathrm{gal}} * 1.1 * 0.90 \\
& =452 \mathrm{lbs}=205 \mathrm{~kg}
\end{aligned}
$$

An initial ash content of $1.5 \%$ by mass implies that the total mass of ash would be 6.77 pounds or $3.07 \mathrm{~kg}$. Approximately two thirds of this total will be rejected in the tails, or about $2 \mathrm{~kg}$.

For a given centrifuge separation ratio $\xi$, and assuming a value of 0.5 mass percent for the maximum ash content in the centrate, the value of ash concentration in the tails would be

$$
\mathrm{C}_{\mathrm{ash}, \mathrm{t}}=0.005 \xi
$$

The total quantity of tails can then be determined from Equation 3, or

$$
\mathrm{m}_{\mathrm{t}}=\frac{\mathrm{m}_{\mathrm{ash}, \mathrm{t}}}{\mathrm{C}_{\mathrm{ash}, \mathrm{t}}}=\frac{2 \mathrm{~kg}}{0.005 \xi}=\frac{400 \mathrm{~kg}}{\xi}
$$


A plot of total quantity of tails versus centrifuge ratio $\xi$ is shown below.

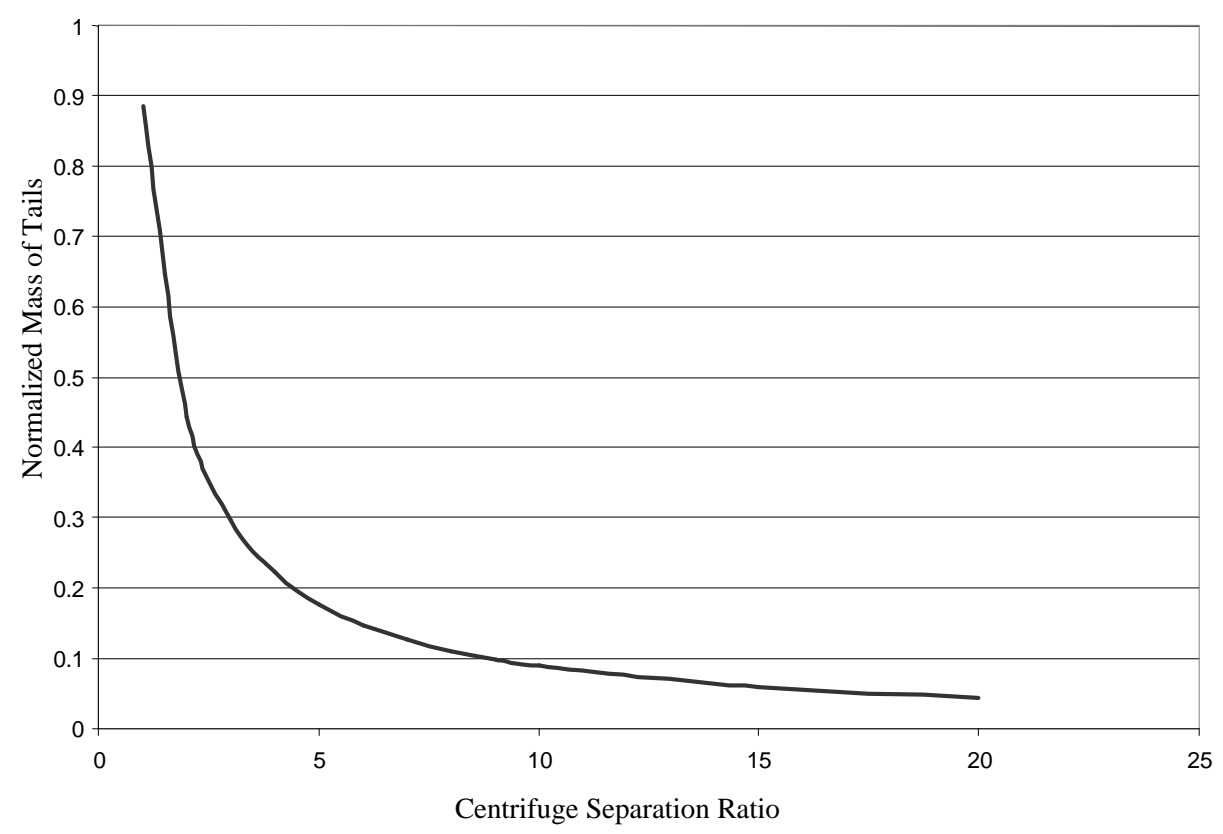

Figure 2. Normalized Mass of Centrifuge Tails Produced as a Function of Centrifuge Separation Ratio.

\subsubsection{Experimental}

A synthetic crude was extracted using bituminous coal (Lower Kittanning seam, with an ash level of about $6 \%$ by mass as measured by proximate analysis). ${ }^{1}$ The solvent was a coal tar distillate obtained from Koppers Inc. and modified via a mild hydrogenation such that the hydrogen concentration was enhanced by about $0.5 \%$ by mass. The coal was dissolved in the solvent at a ratio of 1:3. Total solubility is estimated at $90 \%$ by mass, with the result being a slurry with about $2.5 \%$ solids $(1.5 \%$ ash and $1.0 \%$ fixed carbon) and the balance being a high viscosity hydrocarbon liquid.

Because the centrifuge was designed for operation with motor oil rather than the higher viscosity coal slurry, tests were conducted to determine the effectiveness of the centrifuge. Figures 3 and 4 show that the centrifuge rotational velocity is considerably slower as a function of air pressure when a coal liquid slurry is utilized, but still within the effective operating performance of the device. That is, to obtain equivalent performance with the coal slurry compared to engine oil, it would be necessary to increase the air pressure to the unit by some 40 to $60 \mathrm{psig}$. 


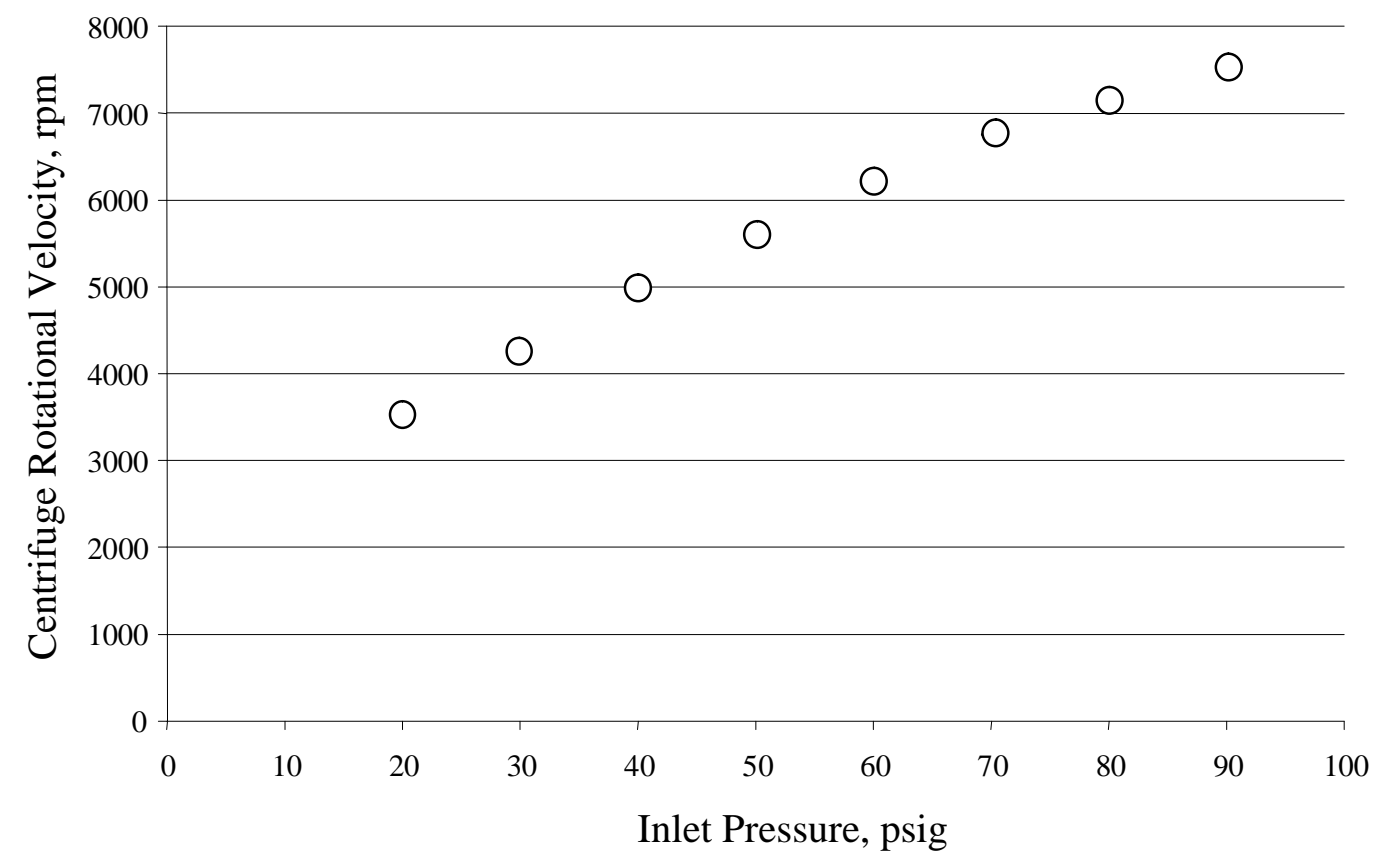

Figure 3. Centrifuge Rotational Velocity with SAE 30 Motor Oil Working Fluid at $75^{\circ} \mathrm{C}$.

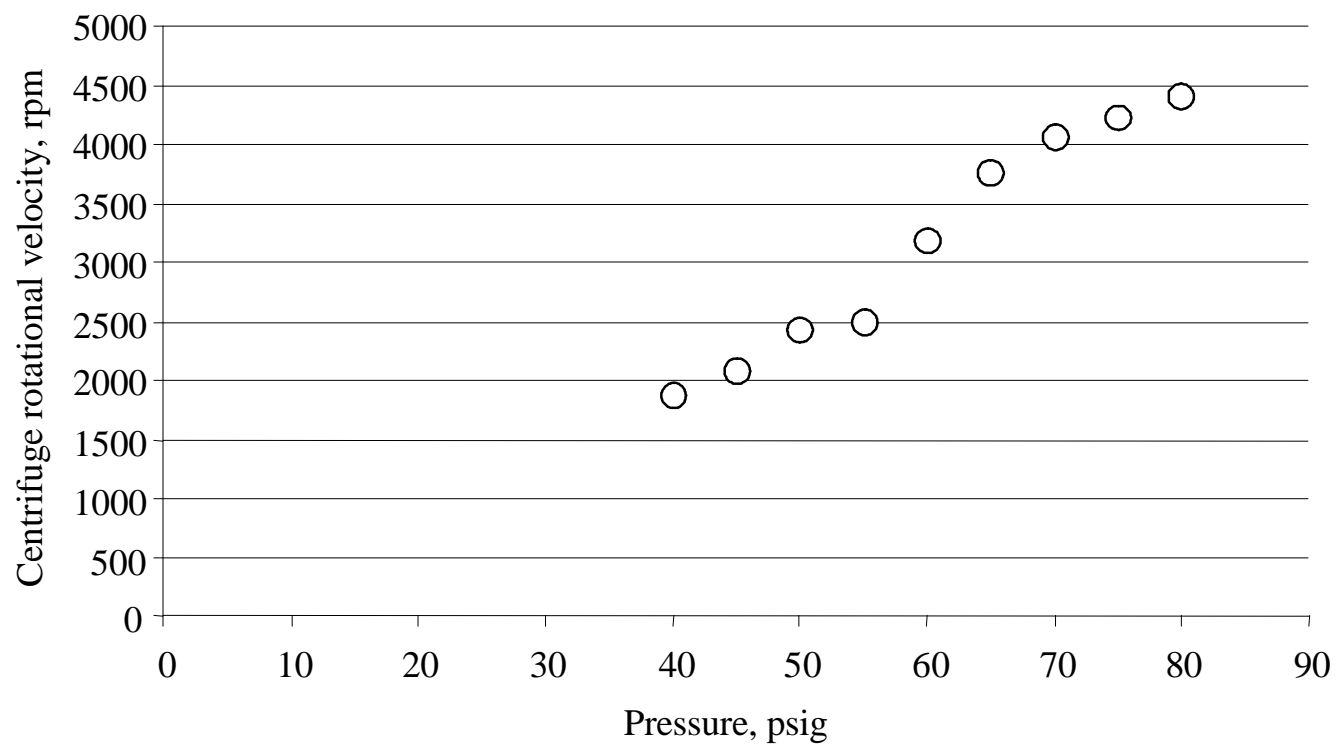

Figure 4. Centrifuge Rotational Velocity with Coal Slurry Working Fluid at $49^{\circ} \mathrm{C}$.

A pressure vessel and return system were designed to allow the continuous operation of the centrifuge. A twenty gallon pressure vessel was outfitted with a bottom outlet valve, a side return valve with internal mixing arm, a top return valve, a top gas inlet for pressurizing, a top gas bleed valve and a top pressure relief valve. During 
operation, the pressure vessel was maintained at a pressure of $60 \mathrm{psig}$ and a temperature of $50^{\circ} \mathrm{C}$. From the tank, the working fluid travels out the bottom valve into the centrifuge. From the centrifuge, the filtered tar is then directed to a reservoir which is open to atmospheric pressure. The 60 psig pressure differential powers the centrifuge. Using a pneumatic pump, the centrate is then pumped back into the pressure vessel (see Figures 5 and 6).

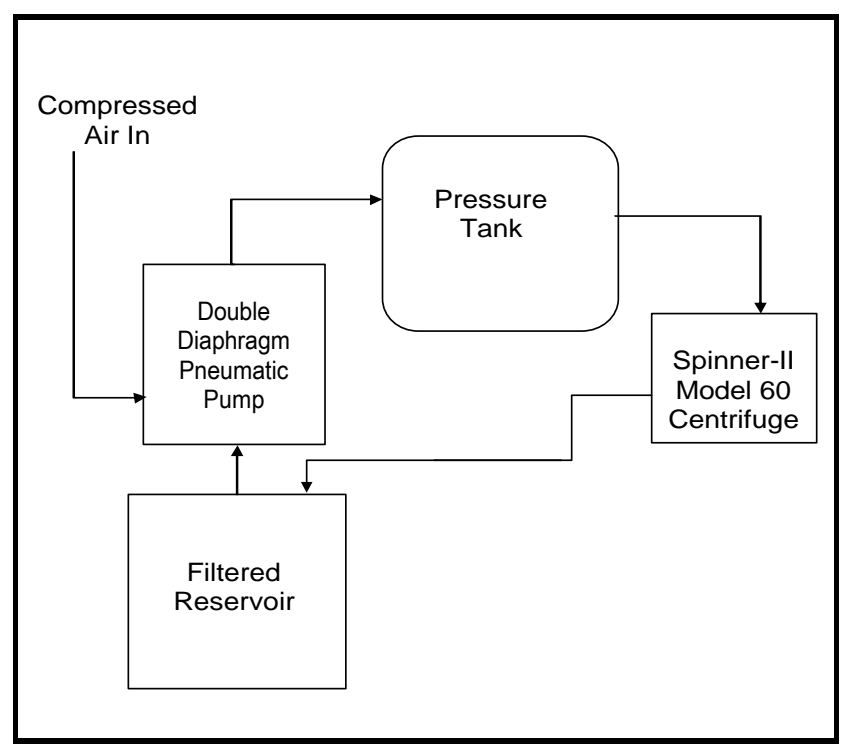

Figure 5. Spinner II Model 60 System Schematic.

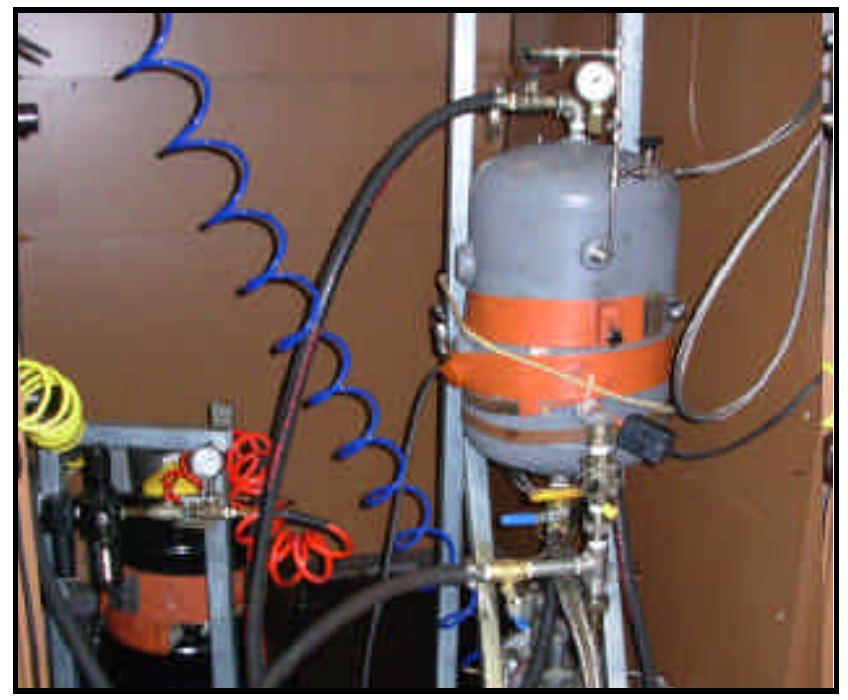

Figure 6. Spinner II Model 60 Centrifuge Experimental Setup.

Heating bands are used to regulate the temperature of the tank at $50^{\circ} \mathrm{C}$. Compressed nitrogen or air is used to bring the pressure vessel to an initial pressure of 65 psig. Upon initiation of the centrifugation process, a pressure of $60 \mathrm{psig}$ is maintained in 
the tank by returning the product under pressure. Through the use of a pneumatic powered return pump, the pressure in the pressure vessel is self regulating and remains fairly constant.

The centrifugation process was timed to determine the effectiveness of the centrifugation over time. Periodically the centrifugation process was stopped to take measurements and to empty the cake from the centrifuge. To stop the process, the bottom feed valve was closed to stop flow to the centrifuge. Any product in the centrifuge was removed with compressed air. The centrate in the reservoir was pumped back into the pressure vessel. The centrifuge was disassembled and the bowl was weighed to determine the mass of the removed solids. Samples were taken of the tails and of the centrate. The bowl was then cleaned and the centrifuge was reassembled. The centrifugation process was then resumed.

The samples were analyzed by proximate analysis according to ASTM D-3172 to determine ash concentrations. The results indicate that the centrifuge significantly reduced the ash levels in the centrate, especially in the first few hours of operation (see Figure 7). The goal of less than $0.5 \%$ ash concentration was met after about seven hours of centrifugation. Somewhat disappointingly, however, the ash levels were no lower than about $0.4 \%$ even after 20 hours of treatment. The ability to produce centrate with $0.5 \%$ ash level would be adequate for the purpose of producing a binder pitch extender, but would not be acceptable if the synthetic pitch thus produced were the majority constituent.

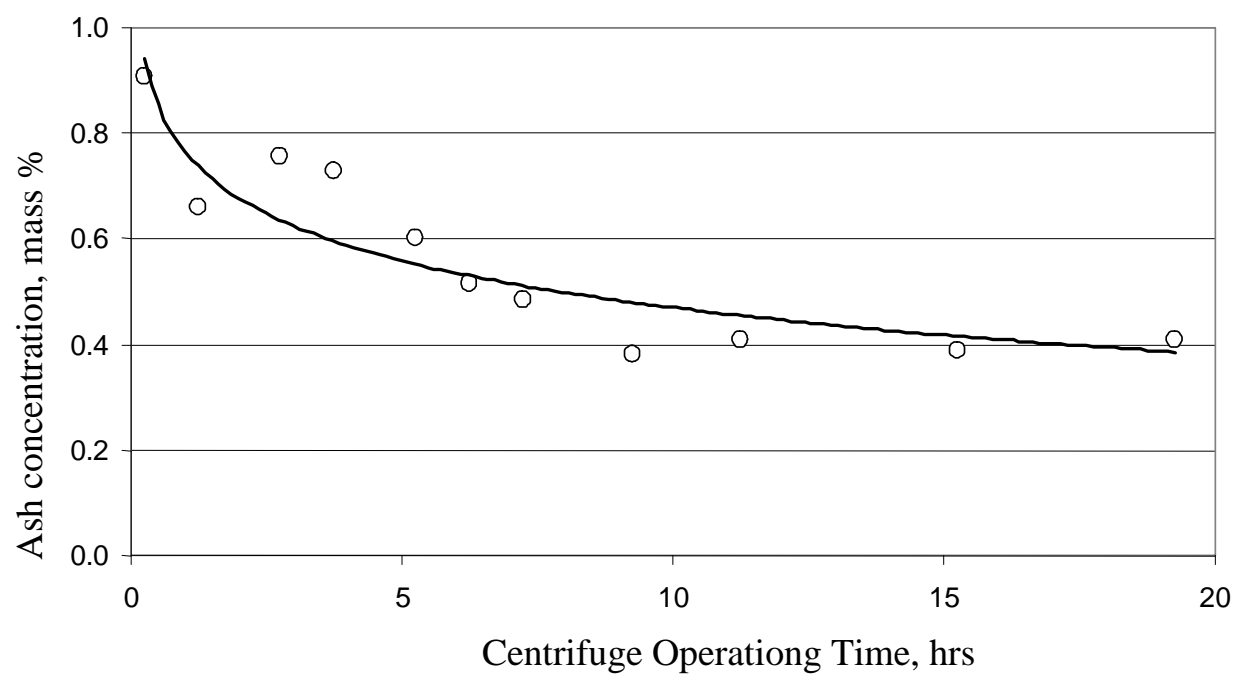

Figure 7. Percent Ash in Coal Derived Tar over Centrifuge Time.

The centrifuge tails were also tested according to ASTM D-3172 to determine the amount of ash present in the tails. Results of these tests correlate with the tests on the centrate. Results show that that the amount of ash in the centrifuge cake was high initially but diminished within several hours of operating time (See Figure 8). 


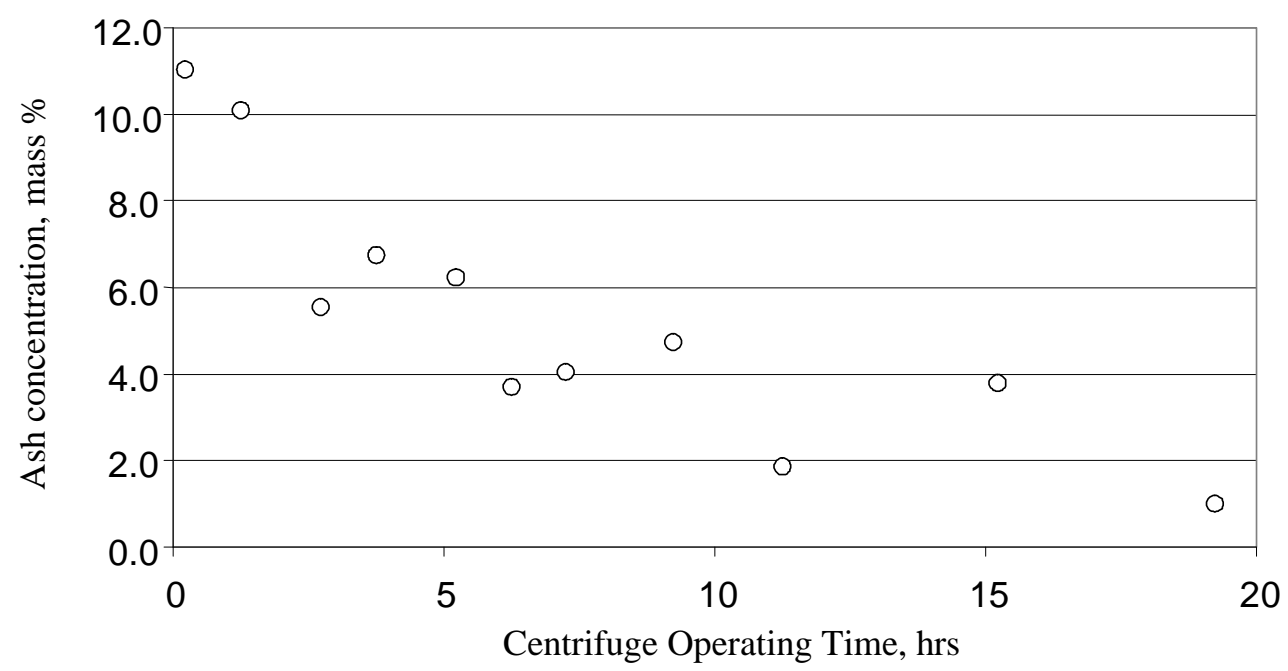

Figure 8. Ash Content in Centrifuge Tails as a Function of Operating Time.

Figure 8 confirms that the centrifugation process was less effective as a function of operating time. This is not unexpected, as the larger, more-easily-removed particles are captured early on, leaving behind smaller particles in the centrate that are more difficult to remove. Figure 9 confirms that after 20 hours, a point of diminishing returns was probably reached.

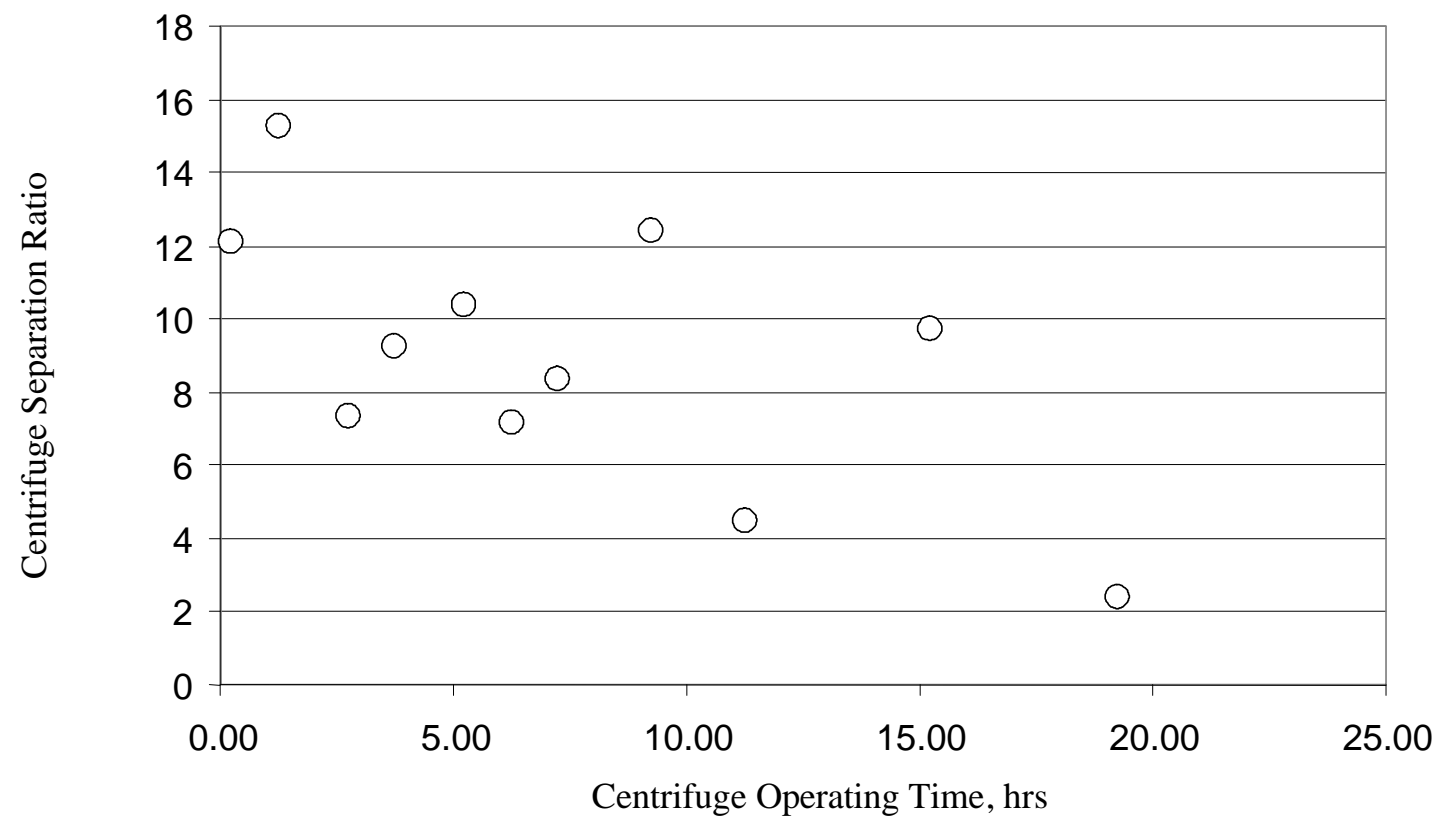

Figure 9. Centrifuge Separation Ratio $\xi$ as a Function of Operating Time. 
In summary, the Spinner-II type centrifuge, although primarily used for removing particulates from engine oil, can be used successfully to remove particulates from coal liquids. A 55 gallon drum would contain about five gallons of centrifuge tails, based on the achieved values of centrifuge separation ratio in Figure 9. Acceptable ash levels were observed in the centrate after several hours of centrifugation, although it proved difficult to achieve ash levels in the centrate below about $0.4 \%$ by mass. Slightly higher temperature might produce better results if the viscosity of the coal liquids is enhanced sufficiently, although the polymer seals used in the device currently limit working fluid temperatures to about $70{ }^{\circ} \mathrm{C}$. Higher pressure would also presumably improve performance, especially the centrifuge separation ratio. Limitations on the in-house air supply prevented the use of higher pressure that might have been able to improve the centrifuge separation ratio.

An additional factor may have been the use of carbon steel pressure vessels and storage drums, which could present an avenue for the generation of metal oxide corrosion products, which would appear as ash during proximate analysis.

\subsubsection{Material Characterization}

Beginning with new batches of coal and coal tar distillate introduces another degree of uncertainty. Therefore, proximate and elemental analyses were carried out in order to verify that the material properties were acceptable. Following hydrogenation, the ratio of aliphatic to aromatic content was measured as a means of verifying the effectiveness of they hydrogenation process.

Three of the drums of coal tar distillate supplied by Koppers were of a much higher viscosity than previously observed. Accordingly, the hydrogenation time was increased to two hours at $1500 \mathrm{psig}$ or higher, and a temperature of $415{ }^{\circ} \mathrm{C}$. Subsequent tubing bomb tests indicate that approximately $90 \%$ of the dry ash free mass was dissolved. Handling the thicker fluid is also a concern for solid separation, because the ability of centrifugation to remove particles is a strong function of the viscosity of the working fluid.

At this time, that concern has not been addressed.

Elemental, proximate and FTIR analyses are contained in Tables 1-4 and Figures $10-15$ 
Table 1. Elemental Analysis of Raw Coal Tar Distillate as-Received from Koppers Inc.

\begin{tabular}{|c|c|c|c|c|}
\hline \multicolumn{5}{|l|}{ Summarize Results } \\
\hline Date : & $3 / 9 / 2007$ & 15:06:30 & & \\
\hline Method Name: & $\mathrm{NCHS}$ & & & \\
\hline Method Filename : & 030907.mth & & & \\
\hline & & & & \\
\hline Group No : 1 & Element \% & & & \\
\hline Sample Name & Nitrogen\% & Carbon\% & Hydrogen\% & Sulfur\% \\
\hline Drum201 raw CTD & 1.009974122 & 92.27355194 & 5.808897018 & 0.599197507 \\
\hline Drum201 raw CTD & 0.966572404 & 92.66756439 & 5.788593292 & 0.549965382 \\
\hline Drum201 raw CTD & 0.986413181 & 92.26402283 & 5.748613834 & 0.536064923 \\
\hline \multicolumn{5}{|c|}{3 Sample(s) in Group No: 1} \\
\hline Component Name & Average & Std. Dev. & \% Rel. S. D. & Variance \\
\hline Nitrogen\% & 0.987653236 & 0.02172741 & 2.1999 & 0.0005 \\
\hline Carbon\% & 92.40171305 & 0.2302833 & 0.2492 & 0.053 \\
\hline Hydrogen $\%$ & 5.782034715 & 0.03067208 & 0.5305 & 0.0009 \\
\hline Sulfur\% & 0.561742604 & 0.03317315 & 5.9054 & 0.0011 \\
\hline Group No : 2 & Element \% & & & \\
\hline Sample Name & Nitrogen $\%$ & Carbon\% & Hydrogen\% & Sulfur\% \\
\hline Drum202 raw CTD & 0.928429961 & 92.40490723 & 6.023236275 & 0.542854786 \\
\hline Drum202 raw CTD & 0.885762453 & 93.3143692 & 6.169347286 & 0.54155457 \\
\hline Drum202 raw CTD & 0.867659509 & 93.22007751 & 6.177357197 & 0.543791056 \\
\hline \multicolumn{5}{|c|}{3 Sample(s) in Group No : 2} \\
\hline Component Name & Average & Std. Dev. & \% Rel. S. D. & Variance \\
\hline Nitrogen\% & 0.893950641 & 0.03120171 & 3.4903 & 0.001 \\
\hline Carbon\% & 92.97978465 & 0.5000858 & 0.5378 & 0.2501 \\
\hline Hydrogen $\%$ & 6.123313586 & 0.08676198 & 1.4169 & 0.0075 \\
\hline Sulfur\% & 0.542733471 & 0.001123167 & 0.2069 & 0 \\
\hline Group No : 3 & Element \% & & & \\
\hline Sample Name & Nitrogen\% & Carbon\% & Hydrogen\% & Sulfur\% \\
\hline Drum203 raw CTD & 0.866767168 & 92.47107697 & 6.242350578 & 0.531380832 \\
\hline Drum203 raw CTD & 0.888844073 & 92.57001495 & 6.296732903 & 0.533972263 \\
\hline Drum203 raw CTD & 0.837415338 & 92.39389038 & 6.289264679 & 0.521841526 \\
\hline \multicolumn{5}{|c|}{3 Sample(s) in Group No : 3} \\
\hline Component Name & Average & Std. Dev. & \% Rel. S. D. & Variance \\
\hline Nitrogen\% & 0.864342193 & 0.02579998 & 2.9849 & 0.0007 \\
\hline Carbon\% & 92.47832743 & 0.08828586 & 0.0955 & 0.0078 \\
\hline Hydrogen $\%$ & 6.276116053 & 0.02947921 & 0.4697 & 0.0009 \\
\hline Sulfur\% & 0.529064874 & 0.006388383 & 1.2075 & 0 \\
\hline
\end{tabular}


Table 2. Proximate Analysis of As-Received Coal Tar Distillate (Drum 202).

\begin{tabular}{|c|r|r|r|r|}
\hline $\begin{array}{l}\text { Crucible } \\
\text { Mass }\end{array}$ & \multicolumn{1}{|l|}{ Analysis Date } & \multicolumn{1}{l|}{ Moisture } & \multicolumn{1}{l|}{ Volatile } & Ash \\
\hline 13.837 & $3 / 8 / 200716: 03$ & 3.02 & 87.01 & -0.07 \\
\hline 13.183 & $3 / 8 / 200716: 03$ & 2.46 & 87.69 & 0.02 \\
\hline 14.122 & $3 / 8 / 200716: 03$ & 2.53 & 87.59 & 0 \\
\hline 15.241 & $3 / 8 / 200716: 03$ & 7.54 & 88.07 & -0.02 \\
\hline 12.592 & $3 / 8 / 200716: 03$ & 7.05 & 88.43 & -0.01 \\
\hline 14.979 & $3 / 8 / 200716: 03$ & 7.69 & 87.69 & -0.02 \\
\hline 15.514 & $3 / 8 / 200716: 03$ & 6.93 & 87.38 & 0.01 \\
\hline 15.294 & $3 / 8 / 200716: 03$ & 9.29 & 85.47 & -0.07 \\
\hline 13.366 & $3 / 8 / 200716: 03$ & 9.71 & 86.4 & 0 \\
\hline
\end{tabular}

Table 3. Elemental Analysis of Kingwood Coal, $1^{\text {st }}$ Drum, As Received.

\begin{tabular}{|c|c|c|c|c|}
\hline \multicolumn{5}{|l|}{ Summarize Results } \\
\hline Date : & $3 / 16 / 2007$ & $15: 00: 28$ & & \\
\hline Method Name: & $\mathrm{NCHS}$ & & & \\
\hline Method Filename: & 031607.mth & & & \\
\hline Group No : 1 & Element \% & & & \\
\hline Sample Name & Nitrogen $\%$ & Carbon\% & Hydrogen $\%$ & Sulfur\% \\
\hline KWCD 1-1 & 1.764131546 & 78.32611847 & 5.321095467 & 2.1706357 \\
\hline KWCD 1-1 & 1.755895972 & 78.48088837 & 5.393305779 & 1.361337185 \\
\hline KWCD 1-1 & 1.693274975 & 76.99646759 & 5.285609245 & 1.959317565 \\
\hline \multicolumn{5}{|c|}{3 Sample(s) in Group No : 1} \\
\hline Component Name & Average & Std. Dev. & \% Rel. S. D. & Variance \\
\hline Nitrogen\% & 1.737767498 & 0.03875106 & 2.2299 & 0.0015 \\
\hline Carbon\% & 77.93449148 & 0.8160301 & 1.0471 & 0.6659 \\
\hline Hydrogen $\%$ & 5.33333683 & 0.05488191 & 1.029 & 0.003 \\
\hline Sulfur\% & 1.83043015 & 0.4197618 & 22.9324 & 0.1762 \\
\hline Group No : 2 & Element \% & & & \\
\hline Sample Name & Nitrogen\% & Carbon\% & Hydrogen $\%$ & Sulfur\% \\
\hline KWCD 1-2 & 1.499559641 & 72.78383636 & 4.784288406 & 3.28338933 \\
\hline KWCD 1-2 & 1.62223208 & 76.0250473 & 5.12075758 & 2.133359194 \\
\hline \multicolumn{5}{|c|}{2 Sample(s) in Group No : 2} \\
\hline Component Name & Average & Std. Dev. & \% Rel. S. D. & Variance \\
\hline Nitrogen\% & 1.56089586 & 0.08674251 & 5.5572 & 0.0075 \\
\hline Carbon\% & 74.40444183 & 2.291882 & 3.0803 & 5.2527 \\
\hline Hydrogen $\%$ & 4.952522993 & 0.2379196 & 4.804 & 0.0566 \\
\hline Sulfur\% & 2.708374262 & 0.8131941 & 30.0252 & 0.6613 \\
\hline
\end{tabular}


Table 4. Elemental Analysis of Kingwood Coal, $2^{\text {nd }}$ Drum, As Received.

\begin{tabular}{|c|c|c|c|c|}
\hline Group No : 3 & Element \% & & & \\
\hline Sample Name & Nitrogen\% & Carbon\% & Hydrogen\% & Sulfur\% \\
\hline KWCD 2-1 & 1.751986861 & 78.27714539 & 5.320038319 & 1.798994184 \\
\hline KWCD 2-1 & 1.791233897 & 79.21688843 & 5.434674263 & 1.599259496 \\
\hline KWCD 2-1 & 1.784820557 & 79.61401367 & 5.495832443 & 1.454648495 \\
\hline \multicolumn{5}{|c|}{3 Sample(s) in Group No : 3} \\
\hline Component Name & Average & Std. Dev. & \% Rel. S. D. & Variance \\
\hline Nitrogen\% & 1.776013772 & 0.02105355 & 1.1854 & 0.0004 \\
\hline Carbon\% & 79.03601583 & 0.6865423 & 0.8686 & 0.4713 \\
\hline Hydrogen $\%$ & 5.416848342 & 0.08924246 & 1.6475 & 0.008 \\
\hline Sulfur\% & 1.617634058 & 0.1729066 & 10.6889 & 0.0299 \\
\hline Group No : 4 & Element \% & & & \\
\hline Sample Name & Nitrogen $\%$ & Carbon\% & Hydrogen\% & Sulfur\% \\
\hline KWCD 2-2 & 1.74025321 & 76.69439697 & 5.276425362 & 1.808419824 \\
\hline KWCD 2-2 & 1.793896198 & 77.67997742 & 5.309375763 & 2.517883778 \\
\hline KWCD 2-2 & 1.808519602 & 78.24575043 & 5.327318668 & 1.722127914 \\
\hline \multicolumn{5}{|c|}{3 Sample(s) in Group No : 4} \\
\hline Component Name & Average & Std. Dev. & \% Rel. S. D. & Variance \\
\hline Nitrogen\% & 1.78088967 & 0.03594374 & 2.0183 & 0.0013 \\
\hline Carbon\% & 77.54004161 & 0.7850866 & 1.0125 & 0.6164 \\
\hline Hydrogen $\%$ & 5.304373264 & 0.02581281 & 0.4866 & 0.0007 \\
\hline Sulfur\% & 2.016143839 & 0.4366564 & 21.658 & 0.1907 \\
\hline
\end{tabular}




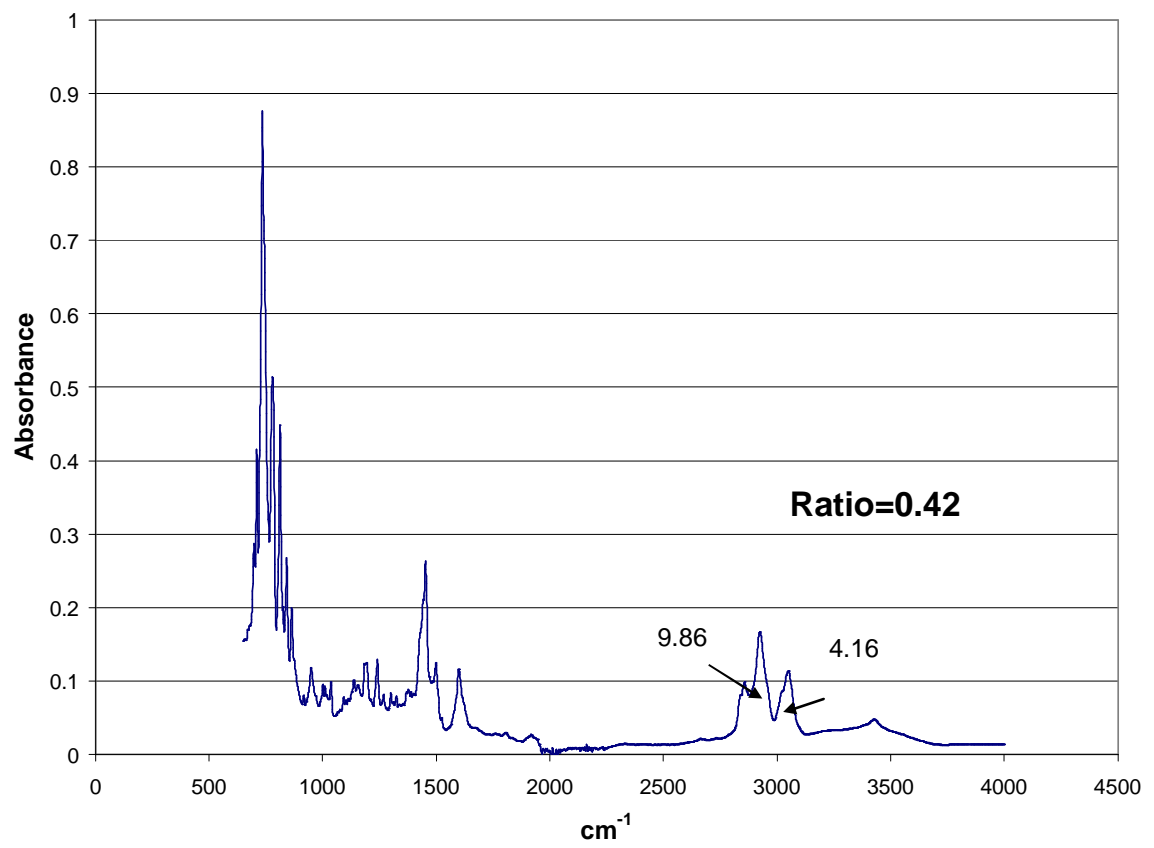

Figure 10. Aromatic to Aliphatic Ratio from FTIR, Hydrogenated CTD, 2/13/07, $1^{\text {st }}$ Run.

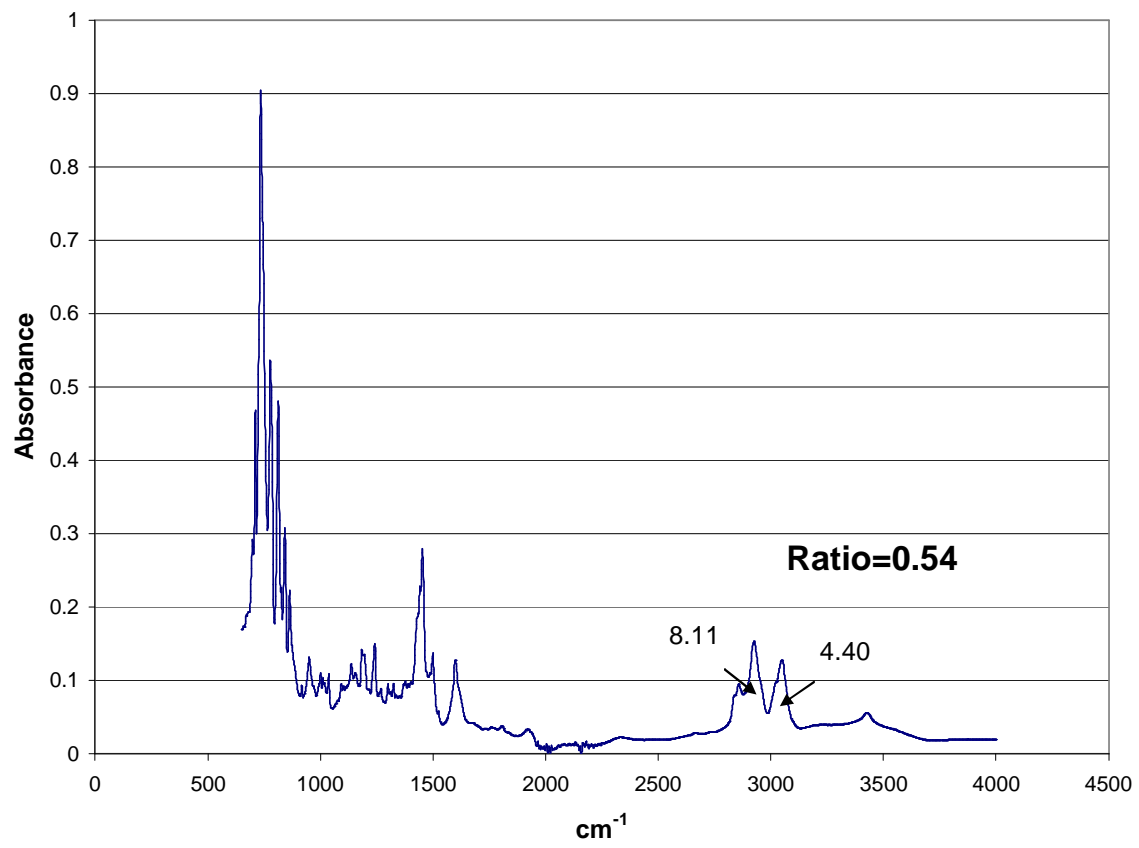

Figure 11. Aromatic to Aliphatic Ratio from FTIR, Hydrogenated CTD, 2/13/07, $2^{\text {nd }}$ Run. 


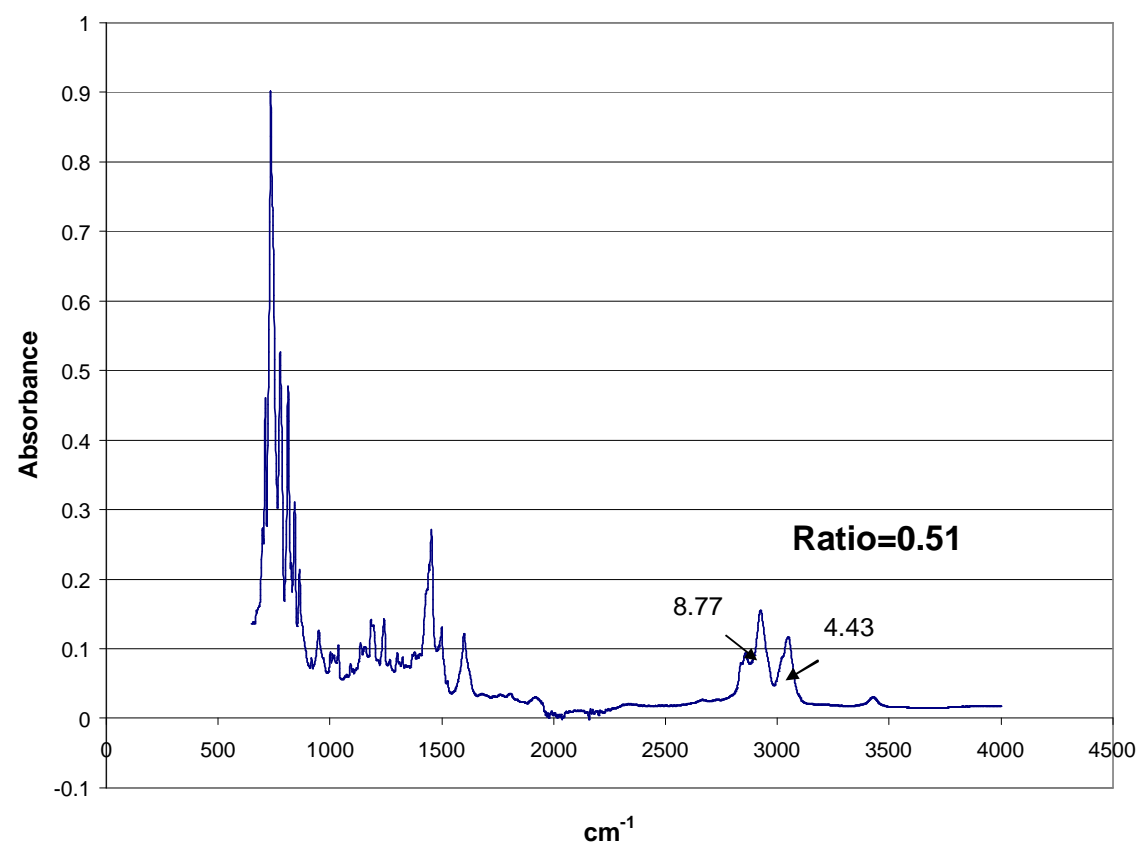

Figure 12. Aromatic to Aliphatic Ratio from FTIR, Hydrogenated CTD, 2/13/07, $3^{\text {rd }}$ Run.

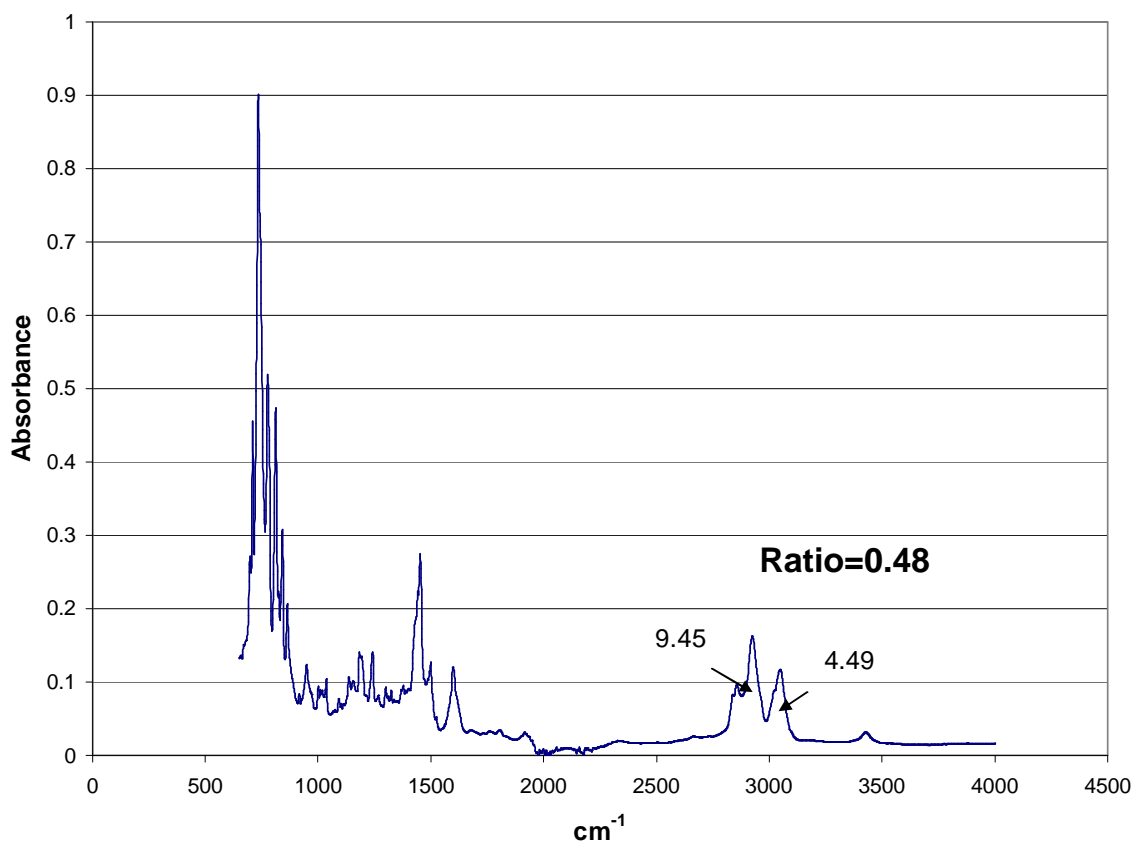

Figure 13. Aromatic to Aliphatic Ratio from FTIR, Hydrogenated CTD, 2/14/07, $1^{\text {st }}$ Run. 


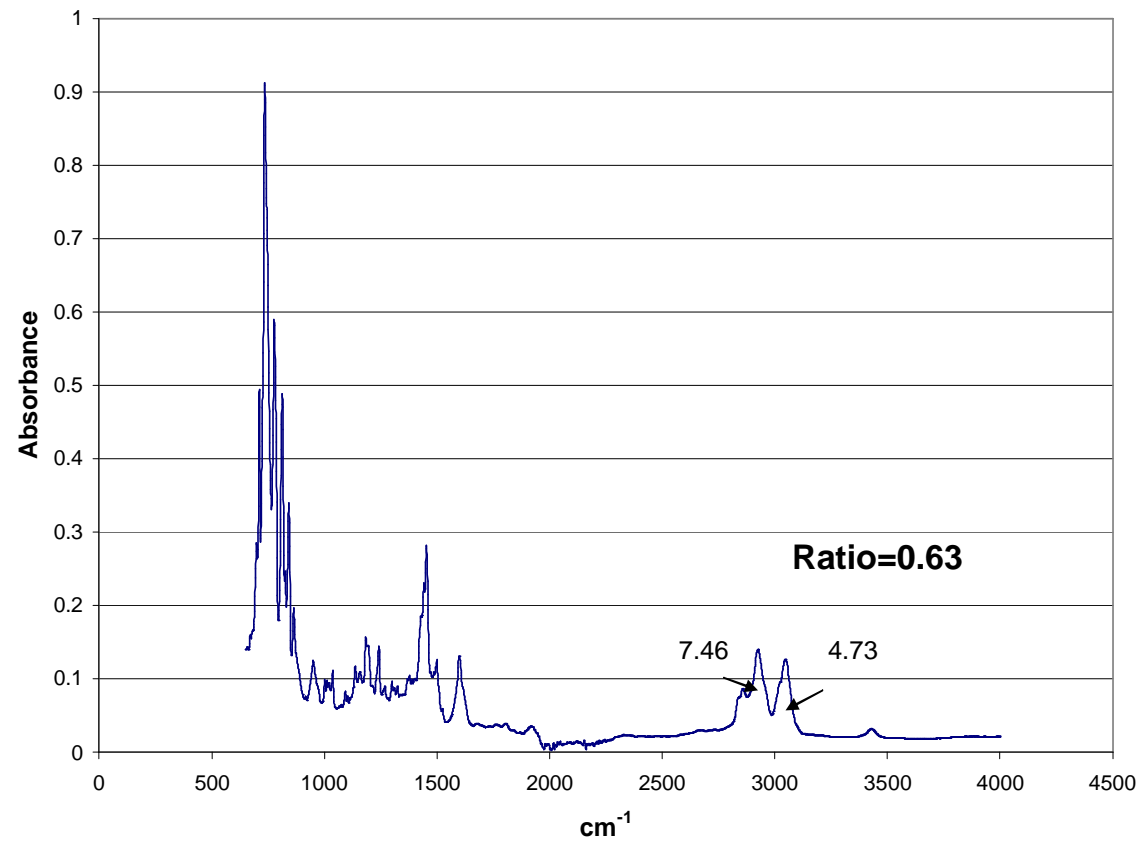

Figure 14. Aromatic to Aliphatic Ratio from FTIR, Hydrogenated CTD, 2/14/07, $2^{\text {nd }}$ Run.

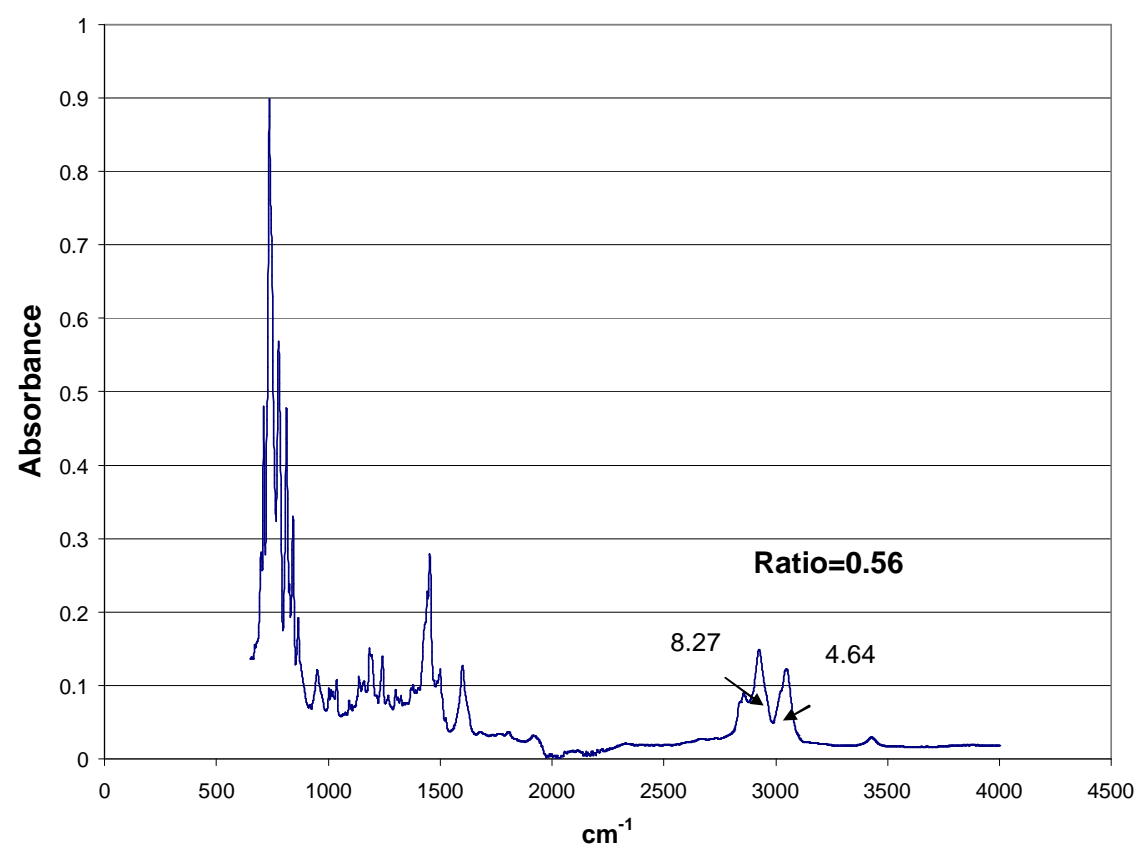

Figure 15. Aromatic to Aliphatic Ratio from FTIR, Hydrogenated CTD, 2/14/07, $3^{\text {rd }}$ Run. 


\subsection{Anisotropic Coke}

An alternate methodology is being considered for creating anisotropic grade (e.g., up to needle grade). The details of the operation of the process are being temporarily withheld pending submission of patents. However, the point is that the ability to increase anisotropy is being sought through variations in coke processing.

\subsubsection{Statistical Design and Analysis}

A $2 \mathrm{k}$ factorial statistical design was selected to screen the effects of temperature and parametric variation on the forming coke. This experimental design and analysis assumes that the effects are linear (Montgomery). Even though this is only approximate it will provide an indication as to which variables have the more significant effect on the mechanically arranged order of the pre-graphitic carbon. The factorial design uses two variables: temperature, and the parametric variation. Mesophase domain growth occurs around $400^{\circ} \mathrm{C}$, so the heat treatment temperatures of $375^{\circ} \mathrm{C}$ and $425^{\circ} \mathrm{C}$ were selected. High (+) and low (-) configurations of the factorial design are shown in Table 5. The table shows a complete series of system configurations for a $2^{\mathrm{k}}$ factorial design (runs 3 6 ) and a control series of control experiments (runs $1 \& 2$ ). The axis, X1, relates to the parametric variation, and X2 is the heat treatment. The main effects as described by equations 2-4, will govern the effectiveness of each parameter.

Table 5. 2k Factorial Experimental Test Sequence (a) Experimental Values (b)

\begin{tabular}{|c|c|c|}
\hline Run & $\mathbf{X 1}$ & $\mathbf{X 2}$ \\
\hline 1 & -1 & 1 \\
\hline 2 & -1 & -1 \\
\hline 3 & 0 & 1 \\
\hline 4 & 0 & -1 \\
\hline 5 & 1 & 1 \\
\hline 6 & 1 & -1 \\
\hline
\end{tabular}

\begin{tabular}{|c|c|c|}
\hline Run & $\mathbf{X 1}$ (\% variation) & $\mathbf{X 2}\left({ }^{\circ} \mathbf{C}\right)$ \\
\hline 1 & 0 & 425 \\
\hline 2 & 0 & 375 \\
\hline 3 & 50 & 425 \\
\hline 4 & 50 & 375 \\
\hline 5 & 100 & 425 \\
\hline 6 & 100 & 375 \\
\hline
\end{tabular}

The main effect of parameter A, B, and the interaction of A and B (AB) is defined as:

a. Main Effect of Parameter A

$$
A=\frac{1}{2 n}[a b+a-b-(1)]
$$

b. Main Effect of Parameter B 


$$
B=\frac{1}{2 n}[a b+b-a-(1)]
$$

c. Interaction Effect of Parameters A and B

$$
A B=\frac{1}{2 n}[a b+(1)-a-b]
$$

Here $n$ is the number of runs. Parameter A represents the heat treatment temperature, Parameter $\mathrm{B}$ represents the parametric variation effects, and $\mathrm{AB}$ represent the interaction effects of parameters $A$ and $B$.

The effects of the induced stress were evaluated over a temperature range of mesophase domain growth. Effectiveness of the temperature and parametric variation was quantified using the main effects (equation $2,3, \& 4$ ). This provides direction to further research of greater depth.

\subsubsection{Pitch Preparation}

The pitch obtained for the experiments was a coal tar pitch from Koppers Inc. The pitch was processed using a vibration separation (VSEP) technique to remove nearly all solvent insoluble material or ash. Using proximate analysis the pitch was tested for moisture, volatile matter, and ash material by weight. The results are shown in Table 6 . It should be noted that a negative ash value is not possible. The ash value is assumed to be zero.

Table 6. Proximate Analysis of Koppers Coal Tar Pitch.

\begin{tabular}{|l|r|r|r|}
\hline \multicolumn{1}{|c|}{ Sample } & \% Moisture & \% Volatile Matter & \% Ash \\
\hline Coal Tar Pitch B1 avg & 0.28 & 35.37 & -0.065 \\
\hline Coal Tar Pitch B2 avg & 0.27 & 37.865 & -0.025 \\
\hline Coal Tar Pitch B3 avg & 0.745 & 52.18 & -0.27 \\
\hline
\end{tabular}

The pitch was then processed using a thermogravimetric analyzer to determine the composition of carbon, hydrogen and heteroatoms, sulfur and nitrogen by weight. Since pitch does not have a defined melting point, it is characterized by the softening point as test by ASTM D-3104. The results are shown in Table 7 and 8, respectively. 
Table 7. Thermogravimetric Analysis of Coal Tar Pitch Material

\begin{tabular}{|c|c|c|c|c|}
\hline Sample & $\begin{array}{c}\text { Nitrogen } \\
\mathbf{\%}\end{array}$ & $\begin{array}{c}\text { Carbon } \\
\mathbf{\%}\end{array}$ & $\begin{array}{c}\text { Hydrogen } \\
\mathbf{\%}\end{array}$ & Sulfur \% \\
\hline Coal Tar Pitch B1 & 1.13 & 91.27 & 4.50 & 0.22 \\
\hline Coal Tar Pitch B2 & 1.09 & 90.66 & 4.35 & 0.18 \\
\hline Coal Tar Pitch B3 & 1.06 & 90.02 & 4.56 & 0.24 \\
\hline
\end{tabular}

Table 8. Mettler Softening Point of the Pitch Material

\begin{tabular}{|l|c|}
\hline Sample & Softening Point $^{\circ} \mathbf{C}$ \\
\hline Coal Tar Pitch B1 avg & 154.2 \\
\hline Coal Tar Pitch B2 avg & 147.7 \\
\hline Coal Tar Pitch B3 avg & 104.2 \\
\hline
\end{tabular}

From Table 8 it can be seen that sample B1 and B2 have similar softening points. As a result material sample B2 was selected for the experiments. If further testing was required material B1 could supplement the material B2 which would have similar material behavior.

The samples of pitch arrived in 5 gallon cans in a solid lump. Each sample of pitch was crush to a granular powder. The void space varied, but approximately $500 \mathrm{ml}$ of pitch was weighed and poured into the reactor.

\subsubsection{Abbreviated Protocol}

A slow flow of nitrogen was applied to the system as the temperature controller was set to the desired devolatilization temperature. The computer and the data acquisition system was initiated and began process parameters. It was found to be advantageous to control the temperature using the process temperature probe in the bottom of the reactor.

The pyrolytic devolatilization of the pitch continued for 5 hours at $375^{\circ} \mathrm{C}$ and 3 hours at $425^{\circ} \mathrm{C}$. Once the molten pitch devolatilized for the prescribed time, the temperature was ramped to approximately $475^{\circ} \mathrm{C}$. The coke seemed to form near this temperature. Then, data acquisition was discontinued, and the heater turned off. Once the reactor cooled to $200^{\circ} \mathrm{C}$ the nitrogen valve was closed. The reactor was then allowed to cool to ambient temperature before obtaining the product.

\subsubsection{Scanning Electron Microscopy.}

The coke was produced by pyrolysis at temperatures of $375^{\circ} \mathrm{C}$ and $425^{\circ} \mathrm{C}$, low and high respectively. The temperature was increased to $475^{\circ} \mathrm{C}$ to ensure that coke had completely formed. 


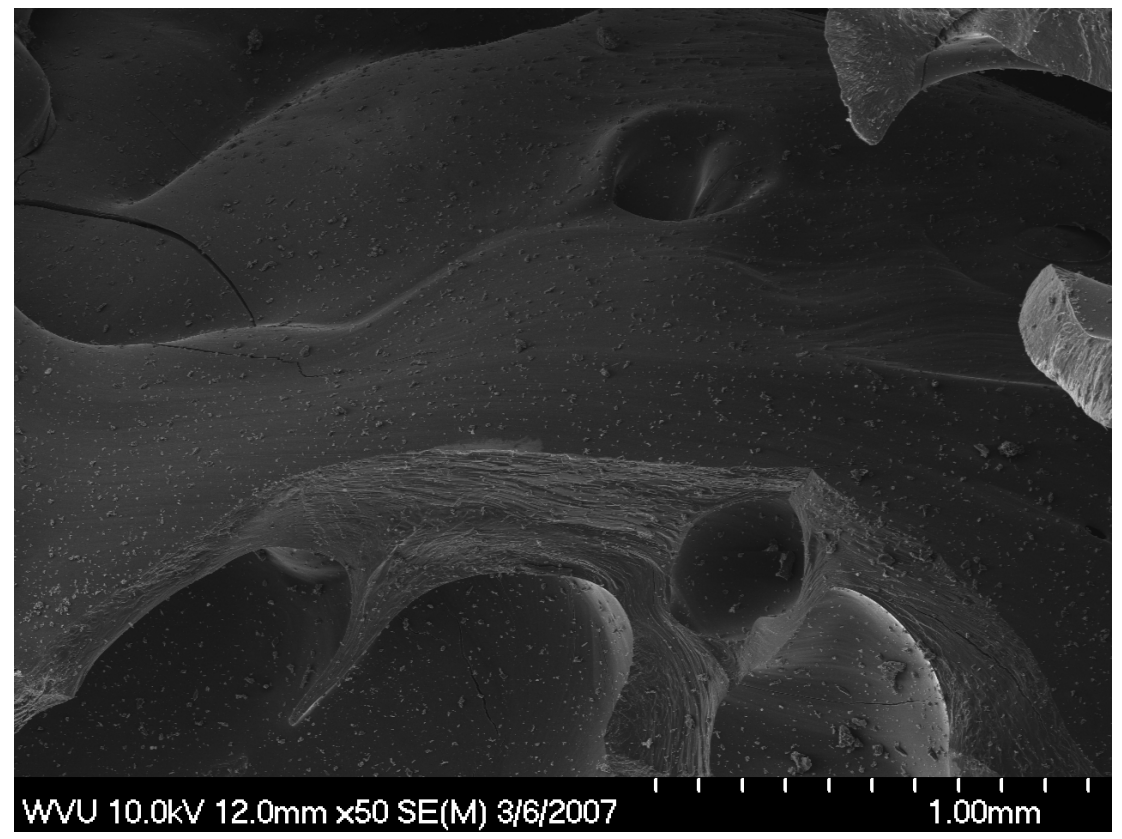

Figure 16. Green Coke Sample T375_0

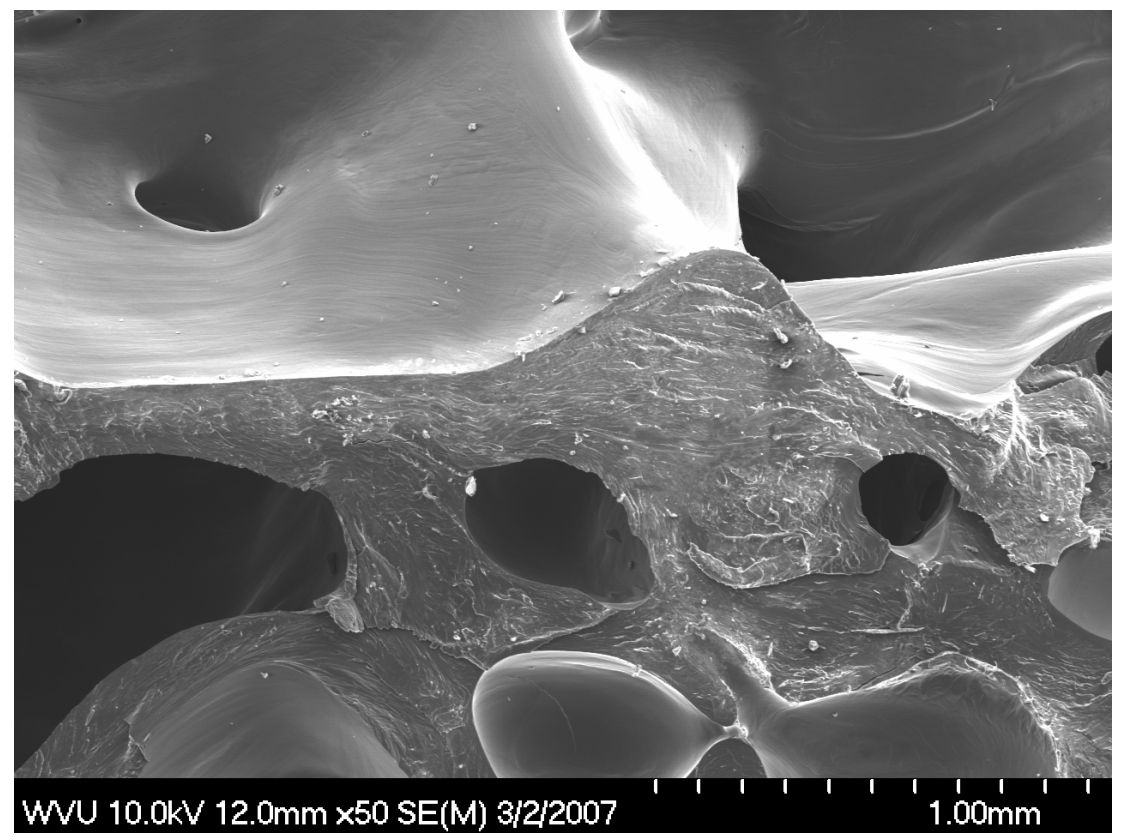

Figure 17. Green Coke Sample T375_0 (2). 


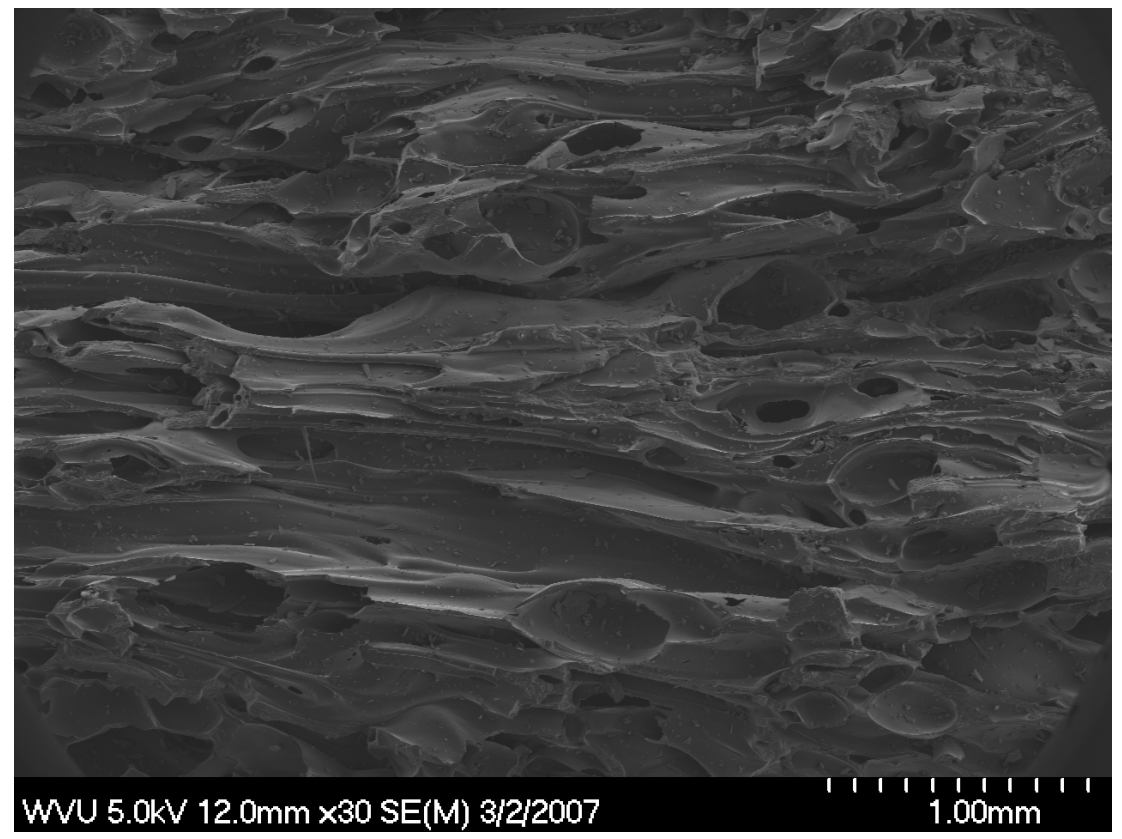

Figure 18. Green Coke from Alternative Process Sample T375_50.

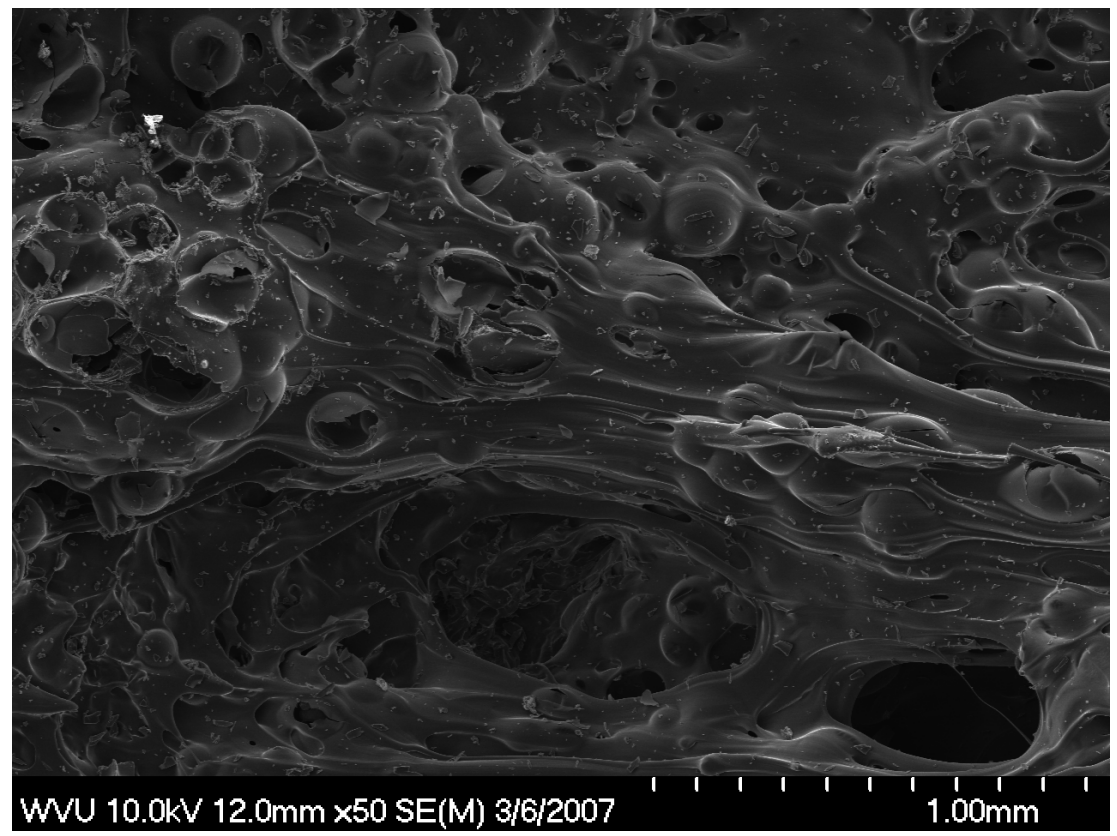

Figure 19. Green Coke from Alternative Process Sample T375_100 


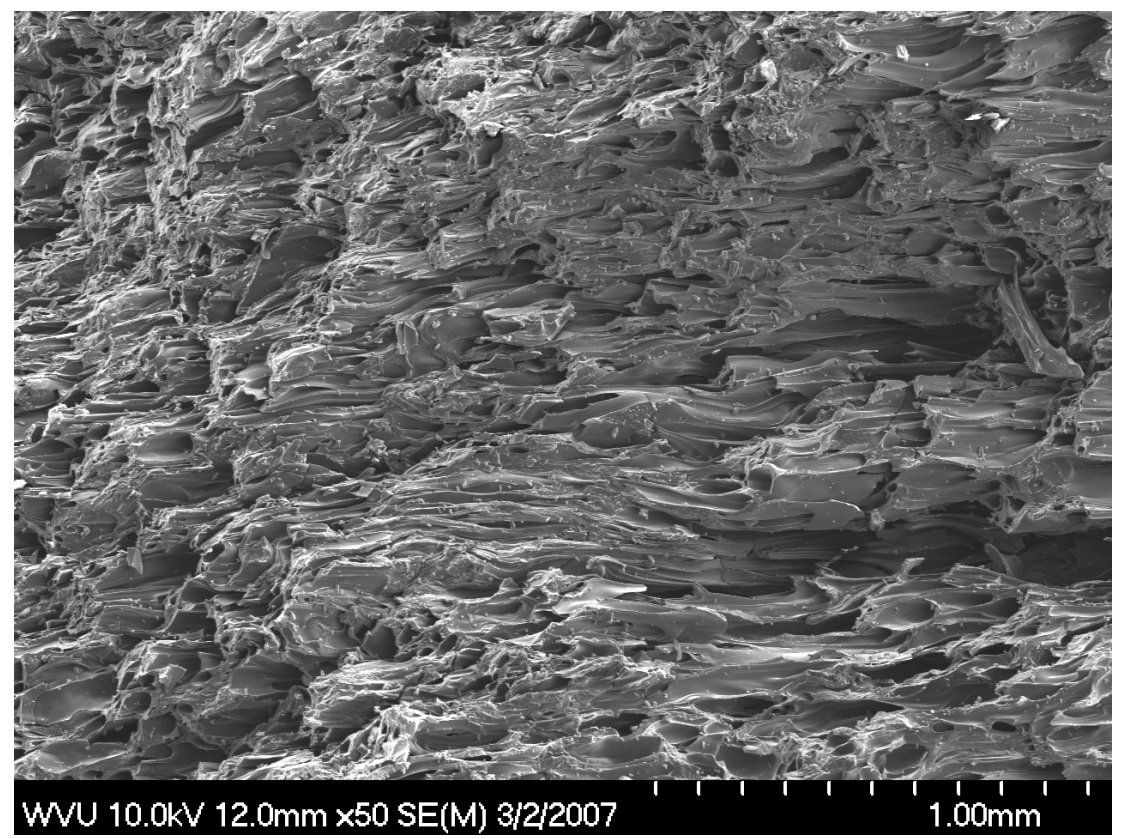

Figure 20. Green Coke form Alternative Process Sample T425_50

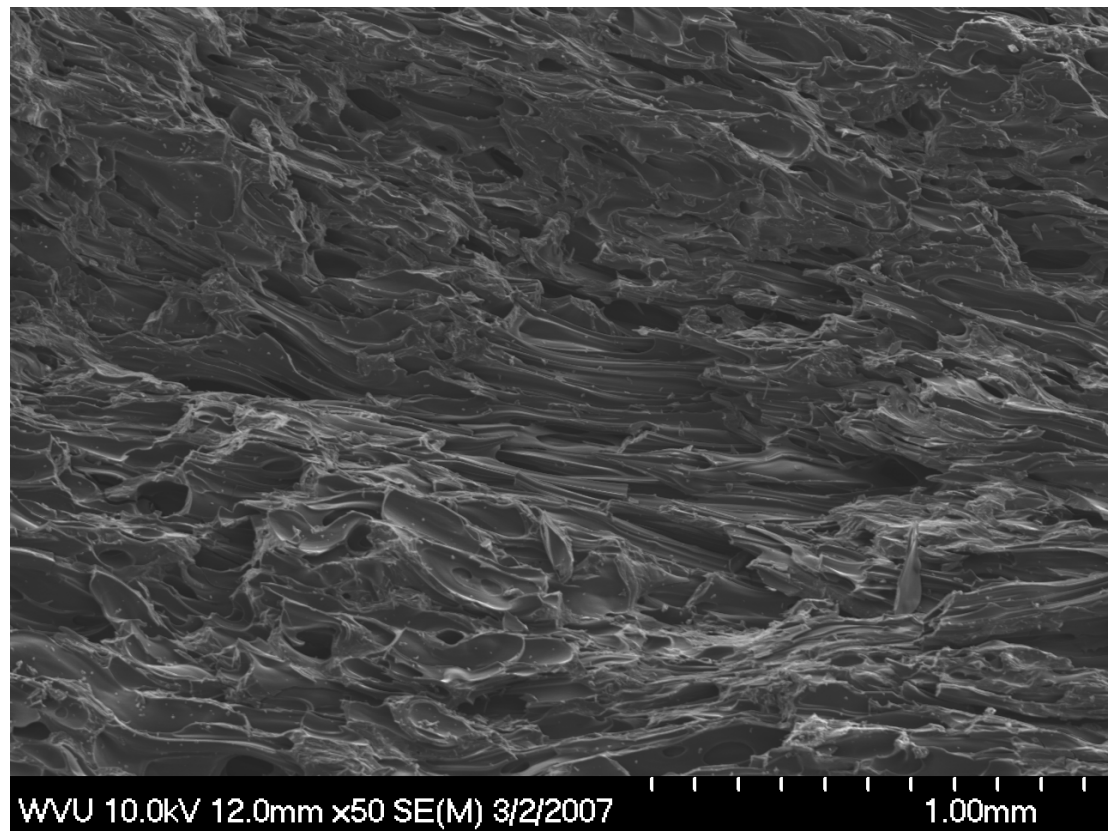

Figure 21. Green Coke form Alternative Process Sample T425_100

X-ray diffraction (XRD) data was corrected for geometric and polarization effects and then plotted in Figure 22. From the corrected data, the peak angle was determined along with the full width at half peak height. This is described by ASTM 5187. The peak values were determined. With this information the crystallite length, $L_{c}$ was 
determined. The $\mathrm{d}_{002}$-spacing between the graphene sheets was then calculated using Bragg's equation,

$$
2 d * \sin \theta=n \lambda,
$$

where $\mathrm{d}$ is the interplanar spacing, $\theta$ is the angle of incidence of the $\mathrm{x}$-ray beam, $\mathrm{n}$ is the order of reflection (integer), and $\lambda$ is the $\mathrm{x}$-ray radiation wavelength (1.54056 $\mathrm{A}$ for copper $\left.\mathrm{K}_{\alpha 1}\right)$.

The data was compiled in Table 9 along with the calculated proportion of disorder from Equation 2.2. It should be noted that Franklin found the d-spacing as a function of graphene plane disorder for graphite. It was calculated in these experiments in an attempt to relate graphitic precursor properties to those of graphite. The observations of the peaks showed that the residual crystalline strain caused a peak shift of the XRD intensity curve (Philips). Until the green coke is heat treated to form graphite, thereby relieving the strains, the peak shift will remain. It would be of interest in further studies to determine if these strains are advantageous or detrimental to the formation of ordered graphite.

Figure 22 shows the randomness function of ordered graphite as a function of dspacing.

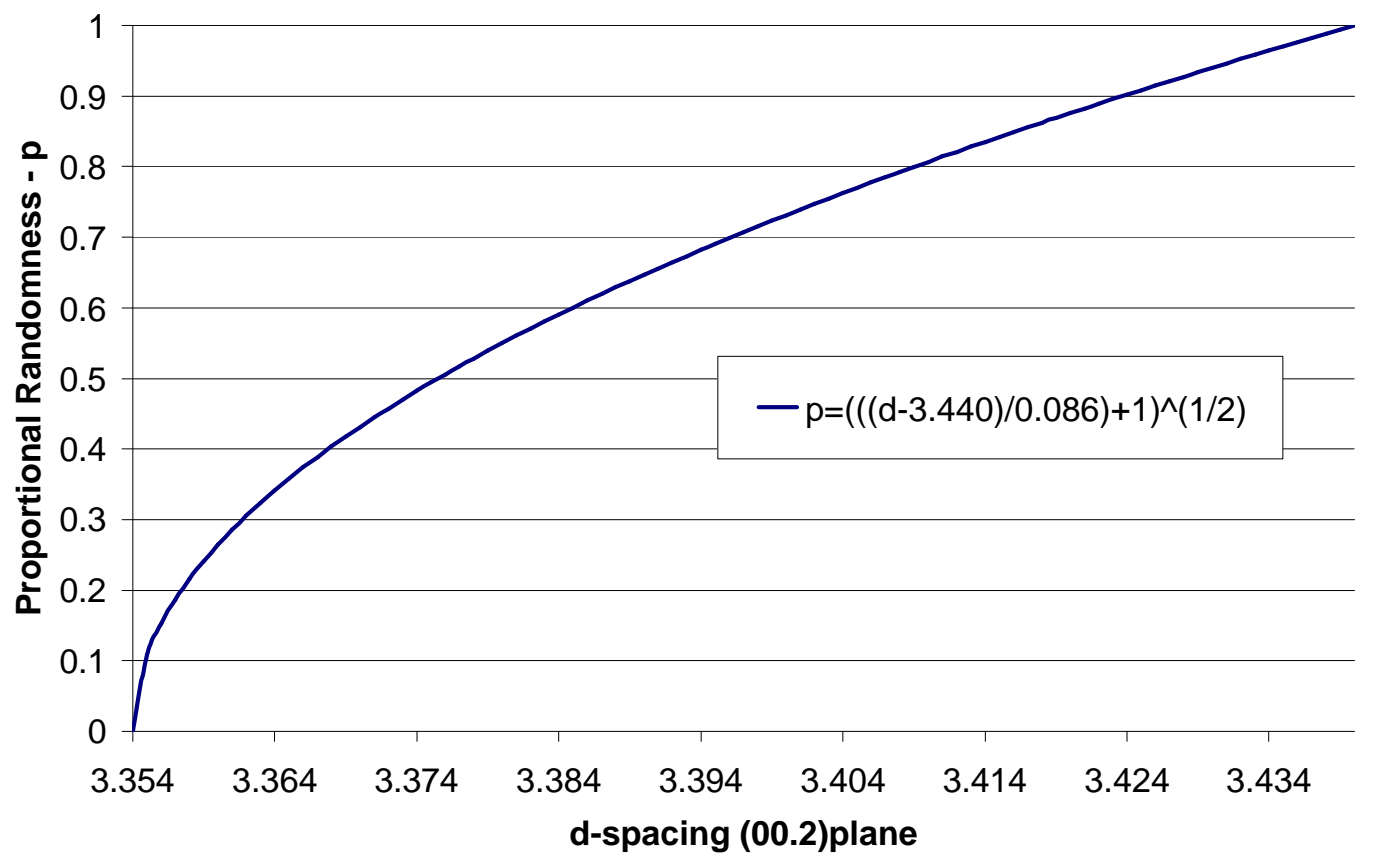

Figure 22. Randomness Function of d-Spacing. 
Table 9. Crystallite Dimensions of XRD 002 Peak

\begin{tabular}{|c|c|c|c|c|c|}
\hline Sample & $\begin{array}{c}\text { FW (theta) } \\
\text { rad }\end{array}$ & $\begin{array}{c}\text { Peak } \\
\text { Location }\end{array}$ & $\begin{array}{c}\text { Crystallite Length } \\
\text { (Lc) }\end{array}$ & $\begin{array}{c}\text { d(002) } \\
\text { spacing }\end{array}$ & $\begin{array}{c}\text { Prop } \\
\text { Disorder }\end{array}$ \\
\hline T375_0 & 0.0436 & 26.15 & 15.7 & 3.4044 & 0.77 \\
\hline T375_50 & 0.0698 & 25.95 & 16.6 & 3.4302 & 0.94 \\
\hline T375_100 & 0.0375 & 25.96 & 18.3 & 3.4296 & 0.94 \\
\hline T425_0 & 0.0428 & 26.07 & 16.0 & 3.4146 & 0.84 \\
\hline T425_50 & 0.0442 & 25.91 & 15.5 & 3.4359 & 0.98 \\
\hline T425_100 & 0.0485 & 25.90 & 14.1 & 3.4369 & 0.98 \\
\hline
\end{tabular}

Coke samples were pulverized to perform x-ray diffraction. The samples were initially crushed with a mortar and pestle. Each sample was placed in a ball mill with ceramic balls. The ball mill was operated until $10 \mathrm{ml}$ of coke was produced in a powder of 160 mesh ( $<98$ microns). The standard test method, ASTM D 5187, calls for 200 mesh ( $<75$ microns) pulverized coke to be scanned.

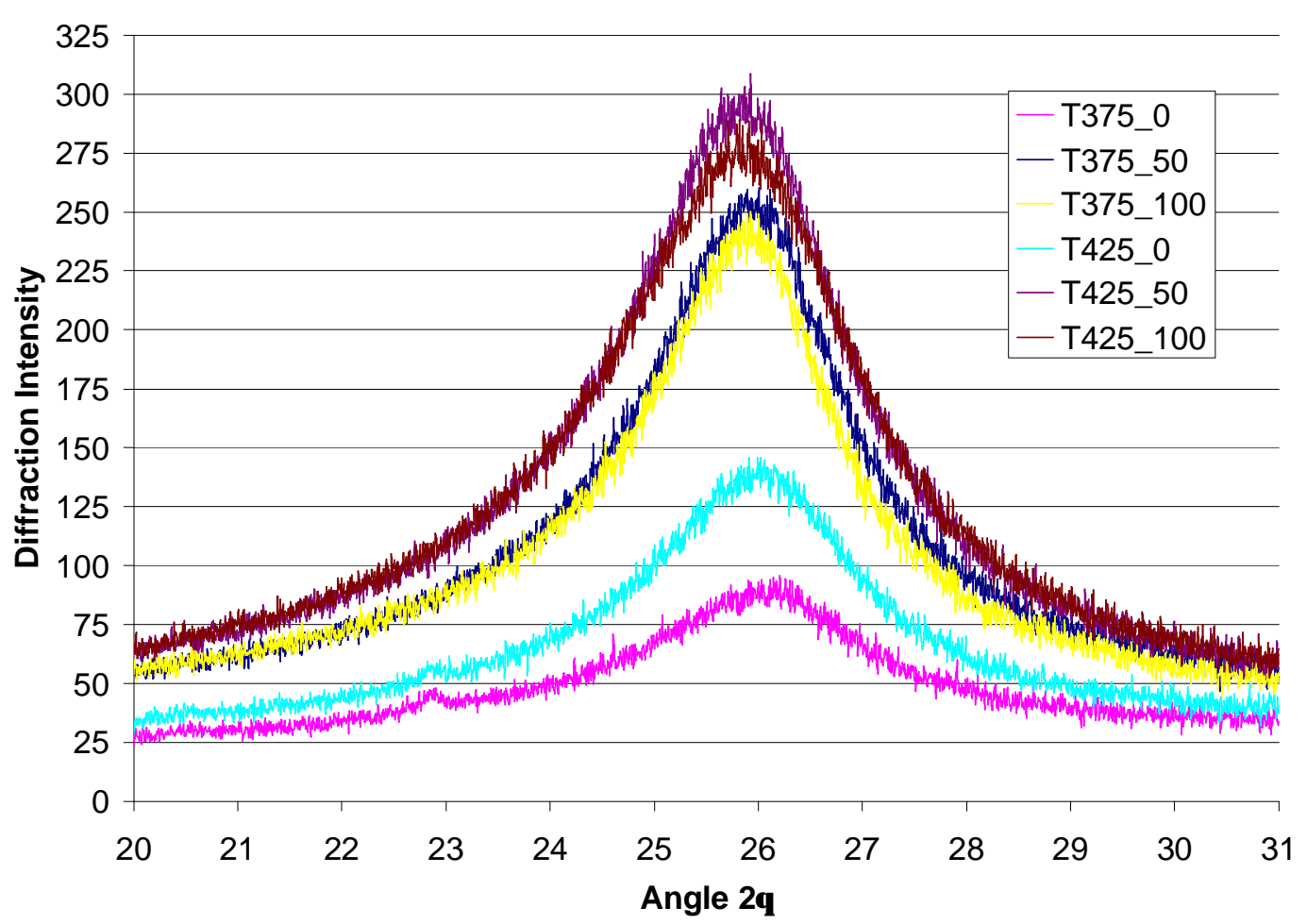

Figure 23. X-Ray Diffraction of Green Coke Samples (shown from 20 to 31 20)

Once the intensity XRD intensity curves were corrected an attempt to reduce the background intensity was made. The background diffraction intensity is a result of scattered x-rays. This is caused by vibration of molecules (temperature), air molecules, as well as amorphous material (Klug and Alexander). The effects will be grouped together as background scatter. In order to compare the differences caused by the 
parameter change, the background intensity was determined. This can be done by establishing a straight line from at the base of the intensity curves. This is illustrated in Figure 24, which shows that the background line averages the fluctuations of the intensity curve. The crystalline intensity is a measure of the integrated region below the sample intensity curve and above the background intensity line for amorphous materials (Klug and Alexander). If the degree of crystallinity is desired, reference materials of amorphous and crystalline structures can be used to establish a proportion of crystallinity.

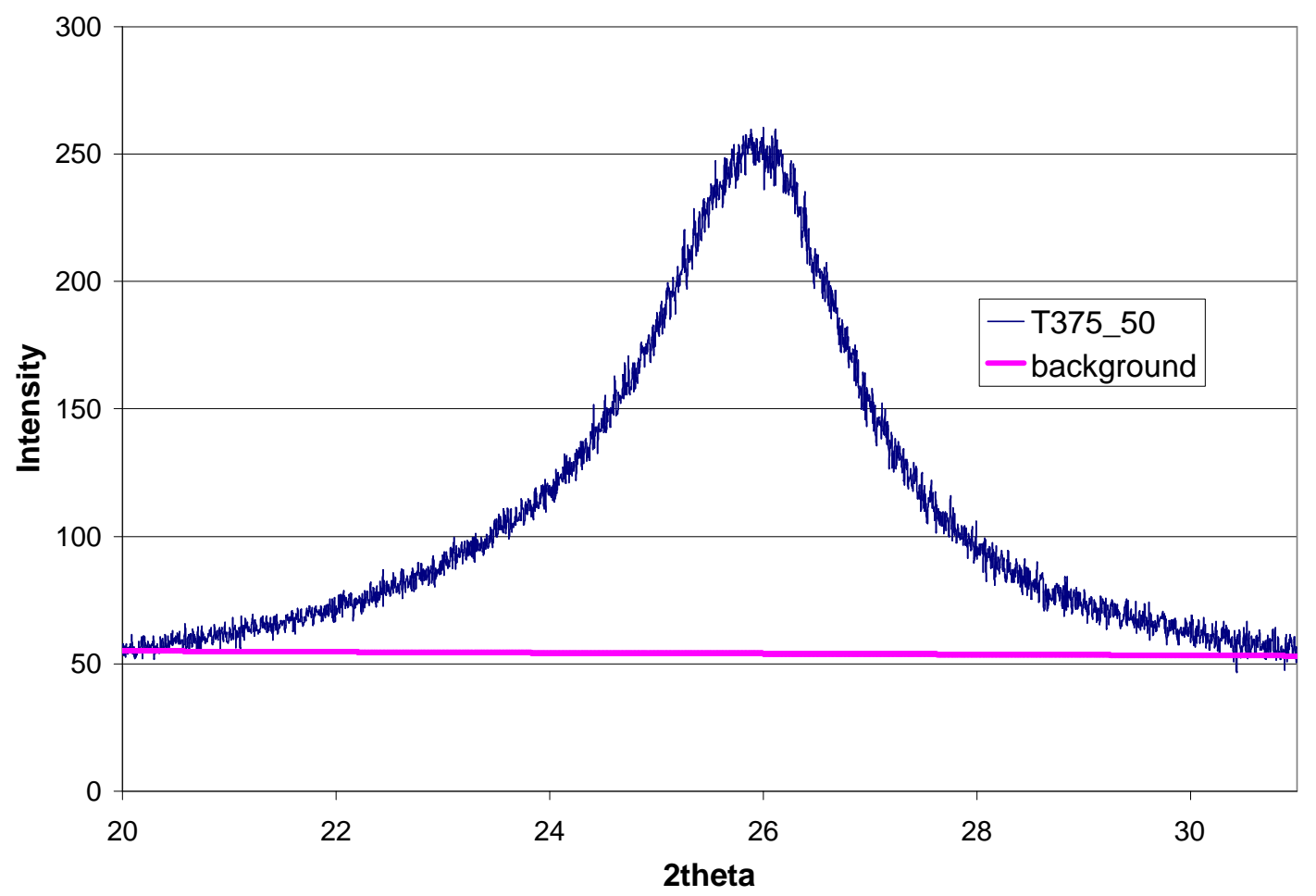

Figure 24. XRD Intensity Curve with Separated Crystalline and Background Region

The main parameter effects were used with the crystalline intensity of each sample to compare parameters. After integrating the region under the intensity curves, the background was subtracted from the total. This value is the crystalline intensity, which is used as the effect obtained from each parameter. Upon calculating the main effects using the statistical analysis it can be seen in Table 10. The value of Block I was calculated for the differences of the parameters for runs $1,2,3, \& 4$ of Table 5 to determine the effects of the parametric variation to a control reaction of temperatures at high and low values. The parametric variation had a significant effect $(B)$ relative to the temperature effect (A). There was no combined effect (AB) observed. Block II was determined for the runs of $3,4,5, \& 6$ of Table 5. Block II represented the effects of $100 \%$ of the parametric variation to the $50 \%$ value of the parametric variation. This data set was to determine the effect of the parametric variation on the crystallinity of the green coke. It can be seen that there was a slight negative effect from increasing the parametric variation (Effect B of Block II). There was a noticeable increase of crystallinity from 
parameter A (temperature). This is consistent with conventional manufacturing techniques used to produce pre graphitic carbon materials. It was noticed that there was a significant effect from the interaction of parameters within Block II.

Table 10. Effects of Parameter Change as a Function of Crystallinity Difference

\begin{tabular}{|l|r|r|}
\hline Parameter & Block I & \multicolumn{1}{c|}{ Block II } \\
\hline Main Effect A (temp.) & 137 & 155 \\
\hline Main Effect B (parameter variation) & 420 & -50 \\
\hline Main Effect AB & -7 & 232 \\
\hline
\end{tabular}

The effects of temperature and parametric variation were determined by a measure of crystallinity. Figure 25 shows the increase of crystalline intensity as a function of temperature change. The temperature has a rather consistent effect on the crystallinity of the carbon. Figure 26 shows the nonlinear effect of shear rate on the crystallinity. From 0 to $50 \%$ of the parametric variation, it can be seen that the crystallinity increased at a similar rate for the two temperature effects. During the increment of $50 \%$ to $100 \%$ of the parametric variation, the values decreased slightly. The other notable difference is that the lines are no longer parallel to each other.

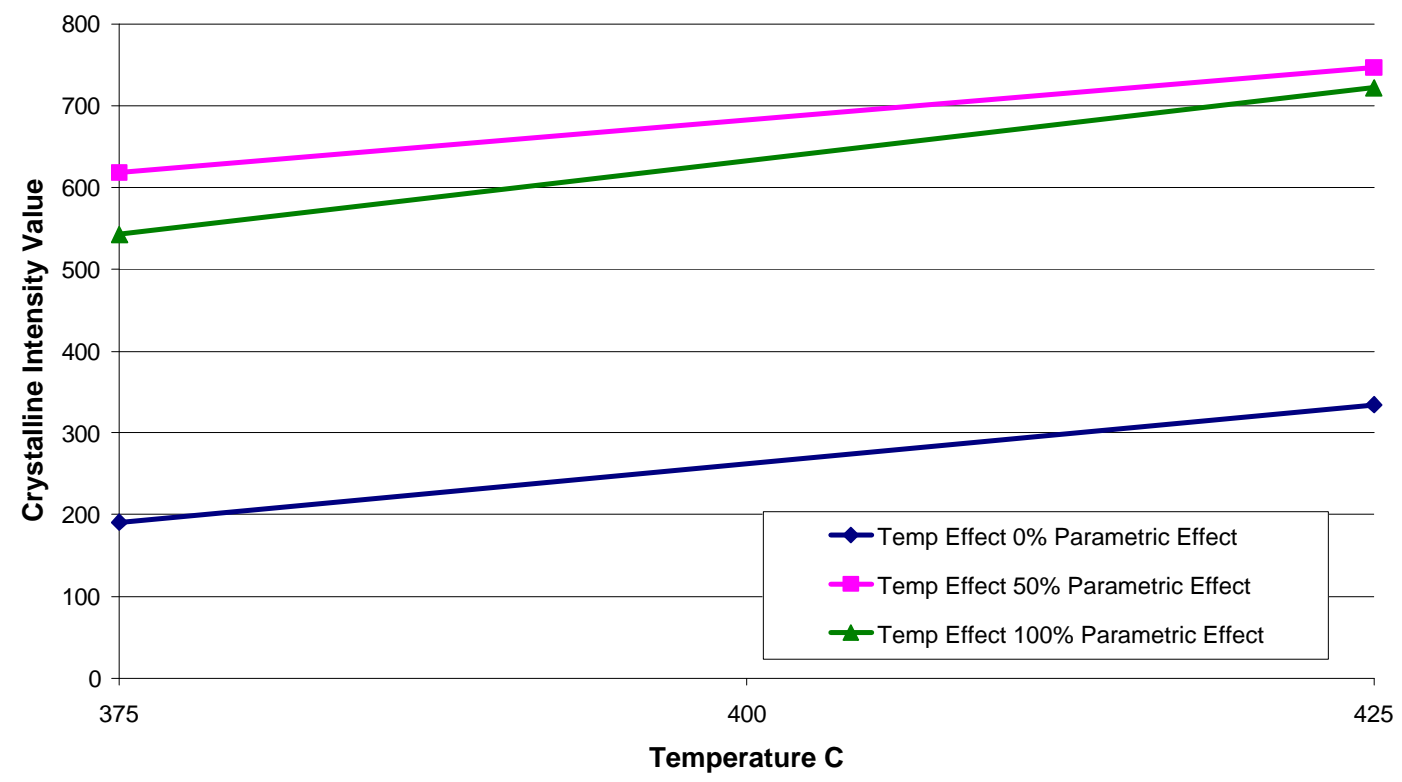

Figure 25. Crystalline Intensity Value as a Function of Temperature 


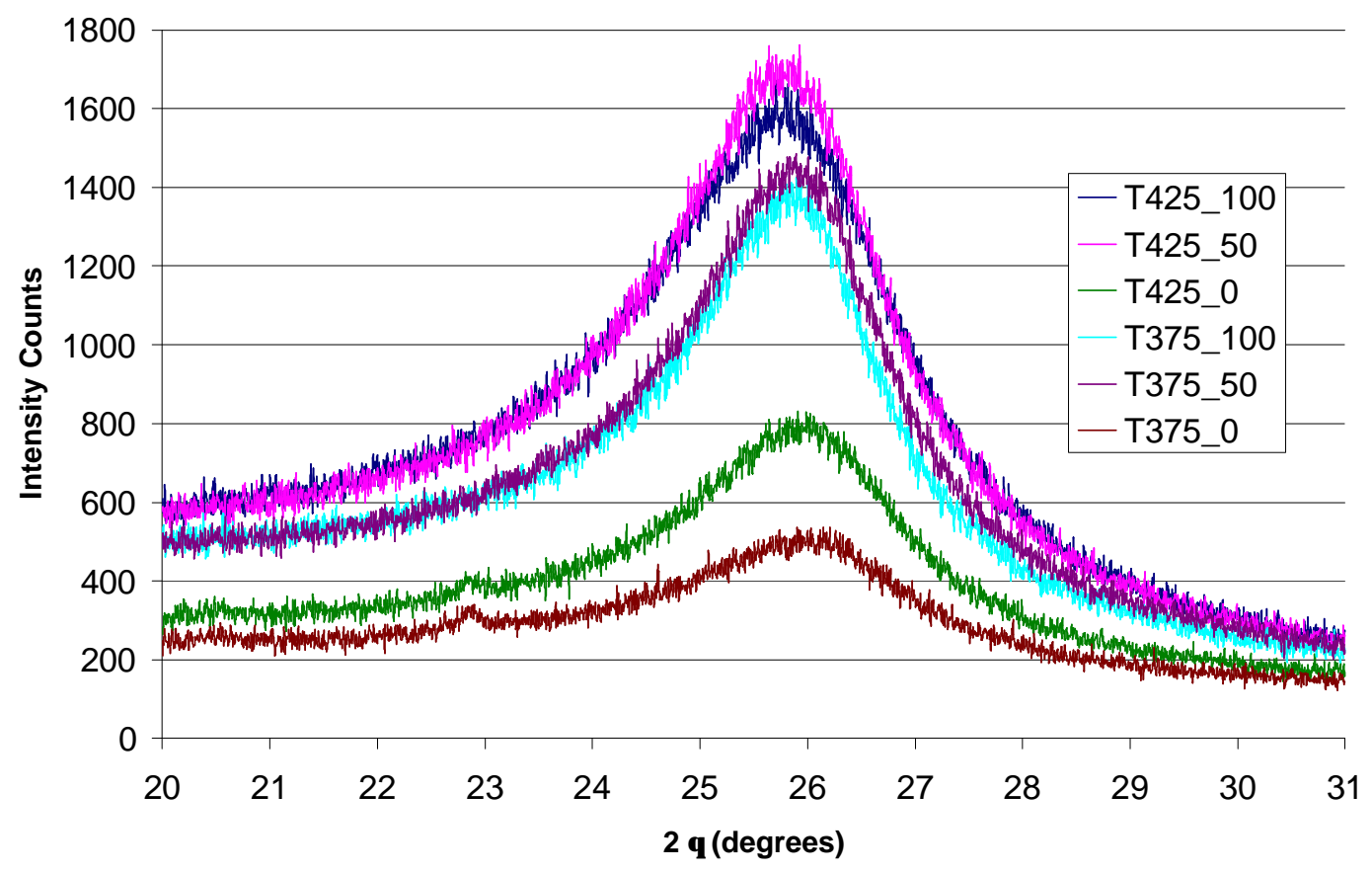

Figure 26. Raw XRD Intensities.

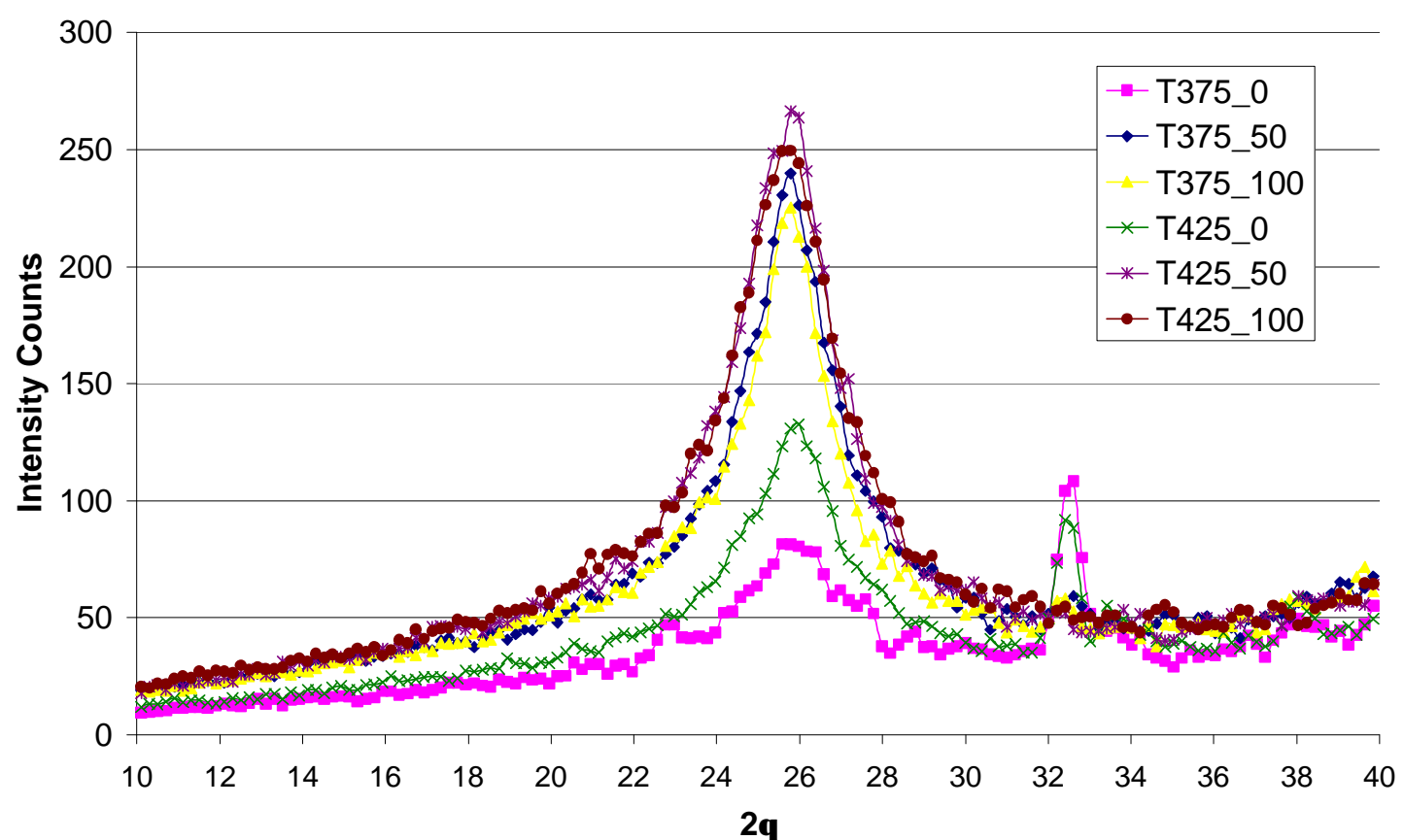

Figure 27. Corrected XRD Intensities.

\subsection{Bibliography}


Askeland, D. R. The Science and Engineering of Materials. 2nd Ed. PWS-Kent Publishing: Boston, 1989.

Azaroff, L. V. and M. J. Bueger. The Powder Method In X-ray Crystallography. McGraw-Hill: New York, 1958.

Bennett, Barbara. Effect of Reaction Parameters Upon Coal and Tire Liquefaction and Coal/Tire Co-Liquefaction Using Two Bituminous Coals. M. S. Thesis, West Virginia University, Morgantown, WV, 1995.

Bragg, L. The Development of X-ray Analysis. Hafner Press: New York, 1975.

Callister, W. D., Jr. Materials Science and Engineering: An Introduction. 3rd Ed. John Wiley \& Sons: New York, 1994.

Charlier, J. -C., X. Gonze, and J. -P. Michenaud, "First-Principles Study of the Stacking Effect on the Electronic Properties of Graphite(s)," Carbon, Vol. 32, No. 2, 1994, pp. 289-299.

Hiroshima, T. et al. "Evaluation of Coker Feedstocks by Quantifying the Fine Mosaic Texture in Laboratory-Produced Coke" Marifu Refinery, Koa Oil Company LTD, 6-1-1 Wakio-Cho, Yamacuchi, 740, Japan, 1995

Klug, H. P. and L. E. Alexander. X-Ray Diffraction Procedures For Polycrystalline and Amorphous Materials. 2nd Ed. John Wiley \& Sons: New York, 1974.

Gray, R. J. and K. F. DeVanney, International Journal of Coal Geology, Vol. 6, 1986, p. 277.

Marsh, H., ed. Introduction to Carbon Science. Butterworths: Boston, 1989.

Marsh, H. and J. Smith. "The Formation and Properties of Anisotropic Cokes from Coals and Coal Derivatives Studied by Optical and Scanning Electron Microscopy." Analytical Methods for Coal and Coal Products. Vol. II, Academic Press: New York, 1978, pp.371414.

McHenry, E. R, et al. "DEVELOPMENT OF ANODE BINDER PITCH LABORATORY CHARACTERIZATION METHODS", Light Metals 1998, pg 769-774.

Montgomery, D. C, Design and Analysis of Experiments $5^{\text {th }}$ Ed. John Wiley \& Sons: New York, 2001.

Orac, T. H. and C. F. Chang. "CTE of Needle Coke-Testing Methods and Significance."

Schultz, J. M. Diffraction for Materials Scientists. Prentice-Hall: Englewood Cliffs, New 
Jersey, 1982.

\subsection{References}

1 E. B. Kennel et al., "Carbon-Rich Product Suites from Direct Liquefaction," The 32nd International Technical Conference on Coal Utilization \& Fuel Systems, June 10 - 15, 2007, Sheraton Sand Key, Clearwater, Florida. 